\title{
Effect of Excess Iron on Oxidative Dehydrogenation of 1-Butene over a Series of Zinc Ferrite Catalysts
}

\author{
Cory Black ${ }^{1}$, Ron R Spence ${ }^{1}$, Keith Whiston ${ }^{2}$, Stephen Sproules $^{1}$ and S David Jackson ${ }^{1 *}$ \\ ${ }^{1}$ Centre for Catalysis Research, University of Glasgow, UK \\ ${ }^{2}$ Invista Textiles (UK) Ltd., the Wilton Centre, UK \\ *Corresponding author: S David Jackson, Centre for Catalysis Research, School of Chemistry, University of Glasgow, Glasgow G12 8QQ UK.
}

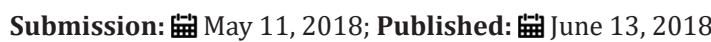

\begin{abstract}
The influence of excess $\mathrm{Fe}^{3+}$ in $\mathrm{ZnFe}_{2} \mathrm{O}_{4}$ for the catalytic oxidative dehydrogenation of 1-butene to 1, 3-butadiene was investigated to try to clarify inconsistencies in the existing literature. A series of nanoscale zinc ferrite powders were produced with increasing Fe: $\mathrm{Zn}$ ratios. The materials were characterized by a range of techniques, which showed the presence of $\alpha-\mathrm{Fe}_{2} \mathrm{O}_{3}$ as a distinct phase with an increasing excess of $\mathrm{Fe}^{3+}$ and SEM highlighted the increased presence of surface structures on the ferrites at higher Fe: $\mathrm{Zn}$ ratios. Reaction testing showed $\alpha$ - $\mathrm{Fe}_{2} \mathrm{O}_{3}$ to be virtually inactive for the oxidative dehydrogenation of 1-butene. Results for the ferrite catalysts showed a significant decrease in both conversion and yield with an increasing excess of $\mathrm{Fe}^{3+}$. Therefore an excess of $\mathrm{Fe}^{3+}$ has a negative effect on catalytic activity and selectivity of zinc ferrite for the oxidative dehydrogenation of 1-butene, but acts as a promoter for competing hydrogenation and combustion side reactions.
\end{abstract}

Keywords: Zinc ferrite; Oxidative dehydrogenation; Butene; 1.3-butadiene; Iron

\section{Introduction}

Armstrong \& Miller [1] discovered 1,3-butadiene in 1886 as a product of his high temperature treatment of petroleum [1], since then 1,3-butadiene has been used for the production of a wide variety of synthetic rubbers and elastomers, in particular styrene-butadiene rubber and polybutadienes, which make up approximately $54 \%$ of the global 1,3-butadiene demand [2]. Butadiene is also used as a raw material in the production of hexamethylene diamine, which is used for Nylon-6, 6 manufactures. Currently, 1, 3-butadiene is almost solely produced from crude oil as a by-product of the steam cracking of naphtha and higher crude oil fractions for the production of ethylene. In recent years the demand for 1,3-butadiene products has been steadily rising and is expected to reach approximately USD 33.01 billion by 2020 [3]. Butadiene yields from steam cracking vary widely with the composition of the refinery feed and are significantly lower for light hydrocarbon feeds derived from shale gas, because of this there is uncertainty about future 1,3-butadiene supply and therefore pricing has driven a considerable amount of interest in alternative methods for producing it by on-purpose through chemical catalysis. Although a variety of other processes have been investigated for the on-purpose production of 1,3-butadiene, such as the Lebedev reaction from ethanol and dehydration routes from butanediols [4], routes employing dehydrogenation of alternative hydrocarbon feeds are the most highly developed. Oxidative dehydrogenation
$(\mathrm{ODH})$ of 1-butene has been shown to be a promising alternative method for 1,3-butadiene production [5,6] and has been practised commercially when economically viable to do so.

A significant body of research exists examining 1-butene ODH over a wide variety of spinel ferrite catalysts [5,7-11] and of the spinel ferrites tested for 1-butene ODH, it has been shown that zinc ferrite is the best catalyst, with 1,3-butadiene selectivity of $\sim 95 \%$ and butane conversion of $\sim 70 \%$ [8]. However other systems have also been tested such as ones based on bismuth and molybdenum. Quite often these systems are modified by other elements, e.g. the addition of nickel to a $\mathrm{BiFe}_{0.65} \mathrm{Mo}$ oxide catalyst [12] but in general these catalysts give a higher selectivity to carbon dioxide than is found with the ferrites. A review of the use of bismuth and ferrite catalysts for 1-butene conversion to 1, 3-butadiene has been published [13]. Iron oxide as $\mathrm{Fe}_{2} \mathrm{O}_{3}$ has also been used for 1-butene conversion but using carbon dioxide as the oxidant [14]. This catalyst system though does not compare well with the ferrite system. The selectivity to 1, 3-butadiene is low $(\sim 25 \%)$ and a higher temperature is needed ( $\sim 823 \mathrm{~K}$ c.f. $743 \mathrm{~K})$ making this an uneconomical prospect compared to either the Bi/Mo or ferrite systems.

The spinel term defines a structure with the formula $\mathrm{AB}_{2} \mathrm{O}_{4}$ where $\mathrm{A}$ is a divalent cat-ion, $\mathrm{A}^{2+}$, and $\mathrm{B}$ is a trivalent cat-ion, 
$\mathrm{B}^{3+}$. There are three types of spinel structure: normal, inverse and random. In a normal spinel the oxygen ions in the structure are arranged in a face centred cubic close packed lattice with $\mathrm{A}^{2+}$ filling 1 in every 8 tetrahedral holes and $\mathrm{B}^{3+}$ in half of the octahedral holes. In an inverse spinel structure $\mathrm{B}^{3+}$ cat-ions would occupy tetrahedral holes with a 1:1 mixture of $\mathrm{A}^{2+}$ and $\mathrm{B}^{3+}$ cat-ions occupying the octahedral holes. Between these two extremes of the spinel structure is the random spinel where $\mathrm{A}^{2+}$ and $\mathrm{B}^{3+}$ cat-ions are distributed randomly between octahedral and tetrahedral holes [15]. Zinc ferrite is known to exist as a normal spinel, where the $\mathrm{Zn}^{2+}$ represents the $\mathrm{A}$ ions and $\mathrm{Fe}^{3+}$ represents the $\mathrm{B}$ ions, however recent literature has shown that at small particle sizes $(<100 \mathrm{~nm})$ there is a degree of inverse spinel character to zinc ferrite, which increases as the particle size gets smaller $[16,17]$.

As 1, 3-butadiene is such a useful and valuable resource, a significant amount of research has been carried out looking at improving zinc ferrite catalyst activity for the ODH of 1-butene. The research has covered a wide variety of different synthesis methods and potential zinc ferrite promoters; including sulphur [6], aluminium [7], phosphoric acid [18], and $\alpha / \gamma-\mathrm{Fe}_{2} \mathrm{O}_{3}[19,20]$. In a study examining a series of biphasic $\mathrm{ZnFe}_{2} \mathrm{O}_{4} / \alpha-\mathrm{Fe}_{2} \mathrm{O}_{3}$ catalysts, the biphasic catalyst exhibited a considerably higher conversion than pure $\mathrm{ZnFe}_{2} \mathrm{O}_{4}$ or $\alpha-\mathrm{Fe}_{2} \mathrm{O}_{3}$ with a maximum conversion of $82.2 \%$ for a $35.3 \% \alpha-\mathrm{Fe}_{2} \mathrm{O}_{3} / \mathrm{ZnFe}_{2} \mathrm{O}_{4}$ catalyst, whilst also showing a high 1,3-butadiene selectivity, 92.6\% [19]. Results also showed that the catalytic activity of the biphasic catalysts was almost entirely independent of the wt.\% $\alpha-\mathrm{Fe}_{2} \mathrm{O}_{3}$ present, indicating that the catalytic activity of the catalyst was due to a synergistic effect between the two phases and not as a result of the phases working independently. It was suggested that the synergistic effect may be the result of a role distribution whereby $\mathrm{ZnFe}_{2} \mathrm{O}_{4}$ activated 1-butene and $\alpha-\mathrm{Fe}_{2} \mathrm{O}_{3}$ activated the gas-phase oxygen, which then spilled over onto the $\mathrm{ZnFe}_{2} \mathrm{O}_{4}$ surface, where the $\mathrm{ODH}$ reaction occurred. A patent filed by Miao et al. [21] in 2004 also revealed very good catalytic activity for a $\mathrm{Zn}_{2.5} \mathrm{AlMgFe}_{10} \mathrm{O}_{20} \mathrm{Z}\left(\alpha-\mathrm{Fe}_{2} \mathrm{O}_{3}\right)$ catalyst used in 1-butene $\mathrm{ODH}$ reactions, where $\mathrm{Z}$ is the percentage by weight of $\alpha-\mathrm{Fe}_{2} \mathrm{O}_{3}$ present. In a catalyst with a $\mathrm{Z}$ value of $54.3 \%$, a 1 , 3-butadiene selectivity and conversion of $91.3 \%$ and $85.9 \%$ were recorded respectively.

In contrast to these works showing $\alpha-\mathrm{Fe}_{2} \mathrm{O}_{3}$ as a 1-butene ODH promoter, Armendáriz et al. [22] carried out work looking at the effect of altering a $\mathrm{ZnFe}_{2} \mathrm{O}_{4}$ catalyst stoichiometry for the oxidative dehydrogenation of n-butane [22]. They showed that by modifying the stoichiometry of their catalyst they could tune the product selectivity of the reaction. They found that the presence of $\alpha-\mathrm{Fe}_{2} \mathrm{O}_{3}$ phase alongside the $\mathrm{ZnFe}_{2} \mathrm{O}_{4}$ phase led to a high selectivity towards $\mathrm{CO}_{2}, \sim 73 \%$. They attributed this effect to increased oxygen lattice reactivity shown by TPR results. A study by Young-Min et al. [23] also produced a zinc ferrite catalyst with $\alpha-\mathrm{Fe}_{2} \mathrm{O}_{3}$ present as a distinct phase and noted that the presence of this additional phase reduced catalytic activity of the zinc ferrite as an oxidative dehydrogenation catalyst. This work set out to determine whether the addition of excess Fe to $\mathrm{ZnFe}_{2} \mathrm{O}_{4}$ improves or impairs catalytic activity for the $\mathrm{ODH}$ of 1-butene to 1,3-butadiene. To tackle this, a series of zinc ferrites with the chemical formula $\mathrm{Zn}_{1-\mathrm{x}} \mathrm{Fe}_{2+\mathrm{x}} \mathrm{O}_{4}(\mathrm{x}=0$, $0.1,0.2,0.3,0.4,0.5$ ) were produced by a co-precipitation method. An in depth study of the catalysts was conducted, including full characterisation of the catalyst pre- and post-reaction and the reaction chemistry.

\section{Experimental \\ Catalyst preparation}

All catalysts were produced by a co-precipitation methodology. $\mathrm{FeCl}_{3} \cdot 6 \mathrm{H}_{2} \mathrm{O}\left(>98 \%\right.$, Alfa Aesar) and $\mathrm{ZnCl}_{2}$ (97\%, Alfa Aesar) were dissolved separately, in stoichiometric proportions, in deionised water. The two metal precursor solutions were then added simultaneously into a rapidly stirring 3M NaOH (98-100 \%, SigmaAldrich) solution. The resultant precipitate mixture $(\sim \mathrm{pH} 11)$ was then left to stir overnight before being washed to $\mathrm{pH}$ neutral through a series of washing and centrifugation steps. The precipitate was dried at $448 \mathrm{~K}$ for $16 \mathrm{~h}$, crushed and sieved to produce a size of between $250-450 \mu \mathrm{m}$ and calcined at $748 \mathrm{~K}$ for $4 \mathrm{~h}$.

\section{Catalyst characterization}

Atomic absorption analysis was obtained using a Perkin Elmer Analyst 400 Atomic Absorption Spectrophotometer with Winlab32 software. An accurately weighed sample of catalyst was dissolved in aqua regia for $30 \mathrm{~min}$ at $393 \mathrm{~K}$ and the resulting mixture diluted 1:1000 with deionised water before analysis. X-ray Photoelectron Spectroscopy (XPS) was performedat the National EPSRC XPS Users' Service (NEXUS) at Newcastle University, an EPSRC MidRange Facility. Measurements were performed on a Thermo Scientific Theta Probe, with a Micro focused monochromatic AlKav source. Data were acquired with pass energy of $40 \mathrm{eV}$ and data analysis was performed using Casa XPS software. Surface area measurements were conducted on a Micrometrics Gemini II 2375 Surface Area Analyser. Catalyst (0.03-0.05g) was accurately weighed, added to a glass sample tube and degassed in nitrogen overnight at a temperature of 383K. The sample was then reweighed and the measurement was taken. The surface area was calculated using the Brunauer, Emmett and Teller (BET) adsorption isotherm equation. Ambient temperature Raman spectroscopy was run on a Horiba Lab RAM HR spectrophotometer. The spectra were collected on a $150 \mathrm{~mW} 562 \mathrm{~nm}$ green laser from 100 to $1500 \mathrm{~cm}^{-1}$. Ambient temperature XRD patterns were obtained using an XPert Pro X-Ray Diffractometer fitted with a reflection/transmission spinning flat plate. The analysis was carried out with a step size of $0.02^{\circ}$ and a scan rate of 30s per step from 5-85 20. X-band EPR spectra were, measured using a Bruker ELEXSYS E500 spectrometer. The zinc ferrite samples were diluted $0.5 \%$ in zinc oxide using a ball mill to achieve a homogeneous powder. Thermo gravimetric analysis was performed on a SDT Q600 series combined TGA/DSC instrument with an online ESS Evolution Mass Spectrometer. For temperature programmed oxidation (TPO) and temperature programmed reduction (TPR), catalyst samples (approximately $0.005 \mathrm{~g}$ ) were heated from ambient to $1000^{\circ} \mathrm{C}$ at a ramp rate of $10^{\circ} \mathrm{C} \mathrm{min}^{-1}$ under a $2 \%$ oxygen balance argon mixture (TPO) or a $5 \%$ hydrogen balance nitrogen mixture (TPR) at a flow rate of $100 \mathrm{~cm}^{3} \mathrm{~min}^{-1}$, whilst mass spectrometry data was collected simultaneously. 


\section{Catalyst testing}

The catalysts produced were tested for 1-butene $\mathrm{ODH}$ in a continuous-flow fixed-bed reactor at ambient pressure. The reactor tube was packed with fused alumina chips with a $1 \mathrm{~cm}^{3}$ catalyst bed in the centre. Experiments with only the fused alumina showed no conversion. The catalyst was heated to $743 \mathrm{~K}$ under a flow of $20 \%$ $\mathrm{O}_{2} / \mathrm{Ar}\left(37.5 \mathrm{~cm}^{3} \mathrm{~min}^{-1}\right)$ and held at temperature for $1 \mathrm{~h}$. The reactor was then cooled to $693 \mathrm{~K}$ and flows of 1-butene $\left(10 \mathrm{~cm}^{3} \mathrm{~min}^{-1}\right)$ and steam $\left(150 \mathrm{~cm}^{3} \mathrm{~min}^{-1}\right)$ were introduced. The steam was produced by pumping an appropriate flow of water with an HPLC pump through a vaporiser. The molar ratio of components in the ODH gas feed was 0.75:1:15 oxygen: 1-butene: steam with an overall GHSV of $10,050 \mathrm{hr}^{-1}$. The reaction was run for approximately $90 \mathrm{~h}$. The eluant from the reactor tube in gaseous form entered a knockout pot where water was condensed. Gaseous samples were subsequently analysed by on-line gas chromatography using a Thermo Scientific Focus Gas Chromatograph equipped with a Flame Ionisation Detector and a Chrompack sodium sulphate on alumina column. GC analysis of the water confirmed only trace levels of dissolved hydrocarbons. The absence of carbon dioxide $(<0.5 \%$ yield) was confirmed by gas chromatography (TCD) and mass spectrometry.

Selectivity and conversion were calculated as outlined in Equation 1 and Equation 2.

Equation 1 - Equation for calculation of conversion. conversion $(C)=\frac{((\text { mol } 1-\text { butene in })-(\text { mol } 1-\text { butene out }))}{(\text { mol } 1-\text { butene in })} \times 100$

This analysis allows for a measure of isomerisation as well as direct oxidative dehydrogenation.

Equation 2 - Equation for calculation of selectivity of product X. selectivity of product $X(S)=\frac{(\text { mol product } X)}{((\text { mol 1-butene in })-(\text { mol } 1-\text { butene out }))} \times 100$

Yield of a product $(\mathrm{Y})$ was calculated by $\mathrm{Y}=\mathrm{C} * \mathrm{~S}$.

\section{Results}

Results are structured to present characterization of the asprepared catalysts, looking at both structural and electronic changes, with increased Fe: Zn ratio. This is followed by a comprehensive analysis of the reaction chemistry and characterization of the postreaction catalysts.

\section{Pre reaction catalyst characterization}

Atomic absorption: Table 1 shows results from atomic absorption spectroscopy performed on the catalyst series. For each catalyst the ratio of Fe: $\mathrm{Zn}$ was calculated from the atomic absorption measurements and compared to its designated target ratio. In all cases the measured ratio was within $10 \%$ of the target, however it can be seen that the correlation between the target and measured ratio is better for the lower Fe: Zn ratio catalyst, suggesting that the excess iron in the catalyst preparation method may affect the co-precipitation at the higher ratios.

Table 1: Atomic absorption results for ferrite catalysts.

\begin{tabular}{|c|c|c|c|}
\hline Molecular Formula & Catalyst Short Name & Target Fe: Zn & Measured Fe: Zn \\
\hline $\mathrm{ZnFe}_{2} \mathrm{O}_{4}$ & $2.0 \mathrm{Fe}$ & 2.0 & 1.9 \\
\hline $\mathrm{Zn}_{0.9} \mathrm{Fe}_{2.1} \mathrm{O}_{4}$ & $2.1 \mathrm{Fe}$ & 2.3 & 2.3 \\
\hline $\mathrm{Zn}_{0.8} \mathrm{Fe}_{2.2} \mathrm{O}_{4}$ & $2.2 \mathrm{Fe}$ & 2.8 & 2.8 \\
\hline $\mathrm{Zn}_{0.7} \mathrm{Fe}_{2.3} \mathrm{O}_{4}$ & $2.3 \mathrm{Fe}$ & 3.3 & 3.7 \\
\hline $\mathrm{Zn}_{0.6} \mathrm{Fe}_{2.4} \mathrm{O}_{4}$ & $2.4 \mathrm{Fe}$ & 4.0 & 4.4 \\
\hline $\mathrm{Zn}_{0.5} \mathrm{Fe}_{2.5} \mathrm{O}_{4}$ & $2.5 \mathrm{Fe}$ & 5.0 & 5.5 \\
\hline
\end{tabular}

XPS analysis: Table 2 details results obtained by XPS, showing the relative percentages of each ion, from which a Fe: $\mathrm{Zn}$ ratio was calculated. Results show a measured Fe: Zn ratio of 5.0 and 9.0 for the $\mathrm{ZnFe}_{2} \mathrm{O}_{4}$ and $\mathrm{Zn}_{05} \mathrm{Fe}_{25} \mathrm{O}_{4}$ respectively. For both catalysts tested the measured Fe: $\mathrm{Zn}$ ratio was far higher than the target one, an indication of excess Fe on the catalyst surface. Atom percentages for
$\mathrm{Fe}^{3+}, \mathrm{Zn}^{2+}$ and $\mathrm{O}^{2-}$ were also calculated, for both the $2.0 \mathrm{Fe}$ and $2.5 \mathrm{Fe}$ catalysts the percentage of $\mathrm{O}^{2-}$ at the surface remains relatively constant at $\sim 71 \%$, however there is a significant decrease in the presence of $\mathrm{Zn}^{2+}$ at the surface of the catalyst as the Fe: $\mathrm{Zn}$ ratio of the catalyst is increased and consequently an increase in surface $\mathrm{Fe}^{3+}$.

Table 2: XPS results for $\mathrm{ZnFe}_{2} \mathrm{O}_{4}$ and $\mathrm{Zn}_{0.5} \mathrm{Fe}_{2.5} \mathrm{O}_{4}$ pre- and post-reaction.

\begin{tabular}{|c|c|c|c|c|c|}
\hline Molecular Formula & Target Fe: Zn Ratio & $\begin{array}{c}\mathbf{F e}^{3+} \\
\text { (Atm \%) }\end{array}$ & $\begin{array}{c}\mathbf{Z n}^{2+} \\
\text { (Atm \%) }\end{array}$ & $\begin{array}{c}\mathbf{0}^{2-} \\
\text { (Atm \%) }\end{array}$ & 70.8 \\
\hline $\mathrm{ZnFe}_{2} \mathrm{O}_{4}$ & 2.0 & 24.3 & 4.9 & 73.8 & 5.0 \\
\hline Post Reaction & 2.0 & 22.4 & 3.8 & 71.0 & 5.8 \\
\hline $\mathrm{Zn}_{0.5} \mathrm{Fe}_{2.5} \mathrm{O}_{4}$ & 5.0 & 26.1 & 2.9 & 76.3 & 12.4 \\
\hline Post Reaction & 5.0 & 21.9 & 1.8 & \\
\hline
\end{tabular}


BET surface area: Table 3 shows results from BET surface area measurements, a significant increase in surface area from $36 \mathrm{~m}^{2} . \mathrm{g}$ ${ }^{1}$ to $71 \mathrm{~m}^{2} \cdot \mathrm{g}^{-1}$ was observed on increasing the catalyst Fe: $\mathrm{Zn}$ ratio from 2:1 to 2.3:1. As the Fe: Zn ratio was further increased the surface area began to decrease with the highest Fe: Zn ratio catalyst,
$\mathrm{Zn}_{0.5} \mathrm{Fe}_{2.5} \mathrm{O}_{4}$, having a surface area of $46 \mathrm{~m}^{2} \cdot \mathrm{g}^{-1}$. An overall increase in average pore diameter was measured with increased Fe: $\mathrm{Zn}$ ratio, with a maximum of $182 \AA$ for $\mathrm{Zn}_{0.5} \mathrm{Fe}_{2.5} \mathrm{O}_{4}$, however total pore volume did not change significantly with increased Fe: Zn ratio.

Table 3: BET surface area measurements for pre- and post-reaction ferrite catalysts.

\begin{tabular}{|c|c|c|c|}
\hline Sample & Surface Area $\left(\mathbf{m}^{2} \cdot \mathbf{g}^{-1}\right)$ & Average Pore Diameter $(\AA)$ & Total Pore Volume $\left(\mathbf{c m}^{3} \cdot \mathbf{g}^{-\mathbf{1}}\right)$ \\
\hline $\mathrm{ZnFe}_{2} \mathrm{O}_{4}$ & 36 & 39 & 0.16 \\
\hline Post-reaction & 15 & 217 & 0.15 \\
\hline $\mathrm{Zn}_{0.9} \mathrm{Fe}_{2.1} \mathrm{O}_{4}$ & 71 & 95 & 0.19 \\
\hline Post-reaction & 12 & 222 & 0.14 \\
\hline $\mathrm{Zn}_{0.8} \mathrm{Fe}_{2.2} \mathrm{O}_{4}$ & 75 & 88 & 0.19 \\
\hline Post-reaction & 21 & 278 & 0.18 \\
\hline $\mathrm{Zn}_{0.7} \mathrm{Fe}_{2.3} \mathrm{O}_{4}$ & 63 & 88 & 0.18 \\
\hline Post-reaction & 3 & 383 & 0.06 \\
\hline $\mathrm{Zn}_{0.6} \mathrm{Fe}_{2.4} \mathrm{O}_{4}$ & 51 & 134 & 0.20 \\
\hline Post-reaction & 4 & 383 & 0.07 \\
\hline $\mathrm{Zn}_{0.5} \mathrm{Fe}_{2.5} \mathrm{O}_{4}$ & 46 & 182 & 0.19 \\
\hline Post-reaction & 9 & 378 & 0.08 \\
\hline
\end{tabular}

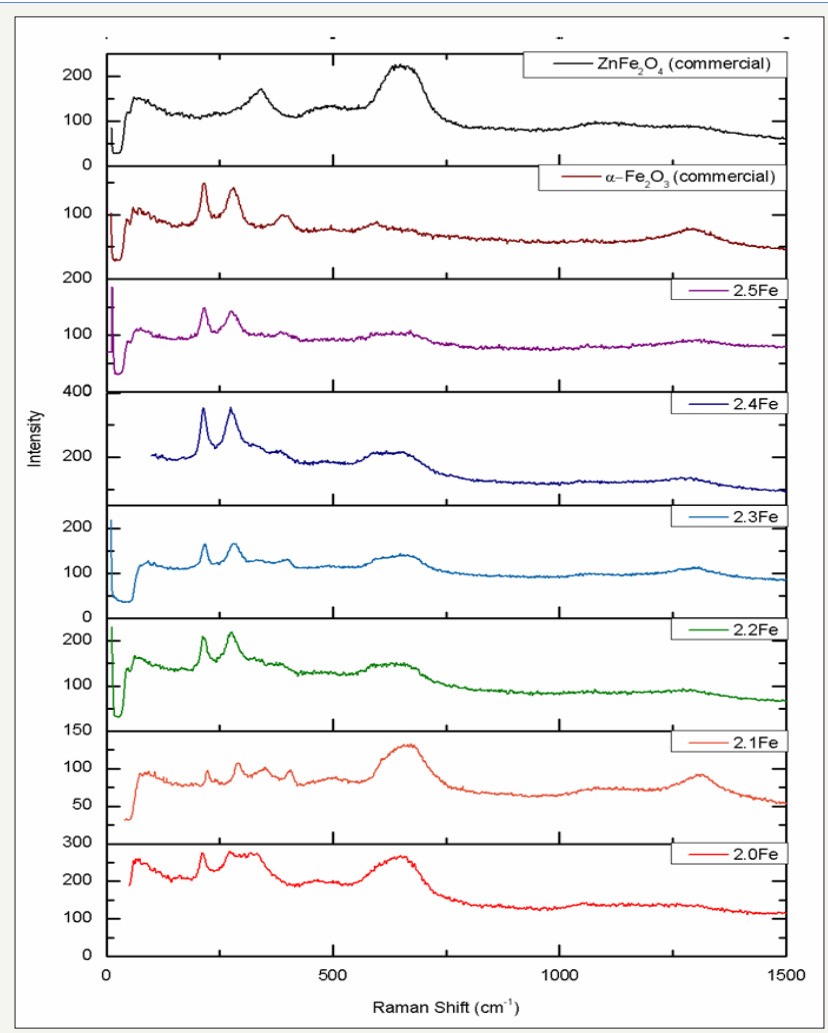

Figure 1: Comparison of Raman spectra for zinc ferrite and iron oxide catalysts.

Raman spectroscopy: $\mathrm{ZnFe}_{2} \mathrm{O}_{4}$ is a member of the space group $\mathrm{Fd} 3 \mathrm{~m}$ and has five first-order Raman active modes, $\mathrm{E}_{\mathrm{g}^{\prime}} \mathrm{A}_{1 \mathrm{~g}}, \mathrm{~F}_{2 \mathrm{~g}}$ (1), $F_{2 g}(2)$ and $F_{2 g}(3)$ [24]. Figure 1 and Table 4 show the Raman spectra and band assignments for the altered $\mathrm{Zn} / \mathrm{Fe}$ ratio catalyst series. It can be seen that the Raman spectra for all of the zinc ferrites produced match up well with both the commercial zinc ferrite sample and examples from the literature [24], indicating that the zinc ferrite phase was successfully produced in all cases. It can be observed however that there are two additional peaks present in the synthesised zinc ferrites, which are not present in the commercial zinc ferrite sample, $\sim 210 \mathrm{~cm}^{-1}$ and $275 \mathrm{~cm}^{-1}$. Although bands at $\sim 221 \mathrm{~cm}^{-1}$ and $246 \mathrm{~cm}^{-1}$ are observed in some literature 
studies looking at the zinc ferrite Raman spectra [24], they are generally of very low intensity and are often not seen at all [25] whereas those observed as part of this work are much more intense and appear to become more intense compared to the remaining zinc ferrite bands, as $\mathrm{Fe} / \mathrm{Zn}$ ratio is increased. Upon visual inspection of the Raman spectra presented in Figure 1 it is clear that the intense bands observed at $\sim 210 \mathrm{~cm}^{-1}$ and $275 \mathrm{~cm}^{-1}$ in the synthesised zinc ferrites are also present in the spectra for $\alpha-\mathrm{Fe}_{2} \mathrm{O}_{3}$. It is therefore hypothesised that $\alpha-\mathrm{Fe}_{2} \mathrm{O}_{3}$ is present in all of the zinc ferrite samples synthesised and that if the $F_{2 g}(1)$ and $E_{g}$ zinc ferrite modes are present in the spectra, that they are being masked by the much more intense $\mathrm{A}_{1 \mathrm{~g}}$ and $\mathrm{E}_{\mathrm{g}}$ bands of $\alpha-\mathrm{Fe}_{2} \mathrm{O}_{3}$ [26]. The remaining $\alpha-\mathrm{Fe}_{2} \mathrm{O}_{3}$ modes are all much less intense and fall at similar Raman shifts to those of zinc ferrite; it would therefore be difficult to distinguish them. Work by Lin et al [27] attributed the broad low intensity peaks at $\sim 1000-1400 \mathrm{~cm}^{-1}$ to a scattering. Which arises from the interaction of two magnons in close proximity which have occurred on anti parallel spin sites.

Table 4: Raman band assignments for ferrite catalysts.

\begin{tabular}{|c|c|c|c|c|c|c|c|}
\hline Assignment & $\begin{array}{l}\text { Raman Modes } \\
\left(\mathrm{cm}^{-1}\right)[23]\end{array}$ & $2.0 \mathrm{Fe}$ & $2.1 \mathrm{Fe}$ & $2.2 \mathrm{Fe}$ & $2.3 \mathrm{Fe}$ & $2.4 \mathrm{Fe}$ & $2.5 \mathrm{Fe}$ \\
\hline$F_{2 g}(1)$ & 221 & 210 & 223 & 212 & 217 & 214 & 214 \\
\hline $\mathrm{E}_{\mathrm{g}}$ & 246 & 276 & 271 & 276 & 281 & 274 & 275 \\
\hline$F_{2 g}(2)$ & 355 & - & 406 & 375 & 400 & 384 & 383 \\
\hline$F_{2 g}(3)$ & 451 & 450 & 454 & 457 & 465 & 476 & 494 \\
\hline$A_{1 g}$ & 647 & 661 & 665 & 640 & 649 & 656 & 671 \\
\hline- & - & 1060 & 1079 & 1078 & 1078 & 1041 & 1092 \\
\hline - & - & 1259 & 1302 & 1273 & 1308 & 1290 & 1318 \\
\hline
\end{tabular}

X-Ray diffraction: X-ray diffraction patterns for the zinc ferrite catalysts are shown in Figure 2. All catalysts showed the characteristic reflections of the zinc ferrite spinel structure. A significant amorphous background was present for all catalysts, which increased relative to the main reflections with increased Fe: $\mathrm{Zn}$ ratio. In the two highest Fe: $\mathrm{Zn}$ ratio catalysts, $2.4 \mathrm{Fe}$ and $2.5 \mathrm{Fe}$, there is an additional peak at $\sim 33^{\circ}$ (highlighted in blue) which does not correspond to zinc ferrite, however it does correlate to a reflection found in the x-ray diffraction pattern for $\alpha-\mathrm{Fe}_{2} \mathrm{O}_{3}$, indicating the presence of $\alpha-\mathrm{Fe}_{2} \mathrm{O}_{3}$ at higher Fe: $\mathrm{Zn}$ ratios. The presence of an $\alpha-\mathrm{Fe}_{2} \mathrm{O}_{3}$ phase being produced alongside the $\mathrm{ZnFe}_{2} \mathrm{O}_{4}$ phase is documented in other studies $[28,29]$. The commercial zinc ferrite sample gave an XRD pattern identical to that for the sample with a Fe: $\mathrm{Zn}$ ratio of 2.0.

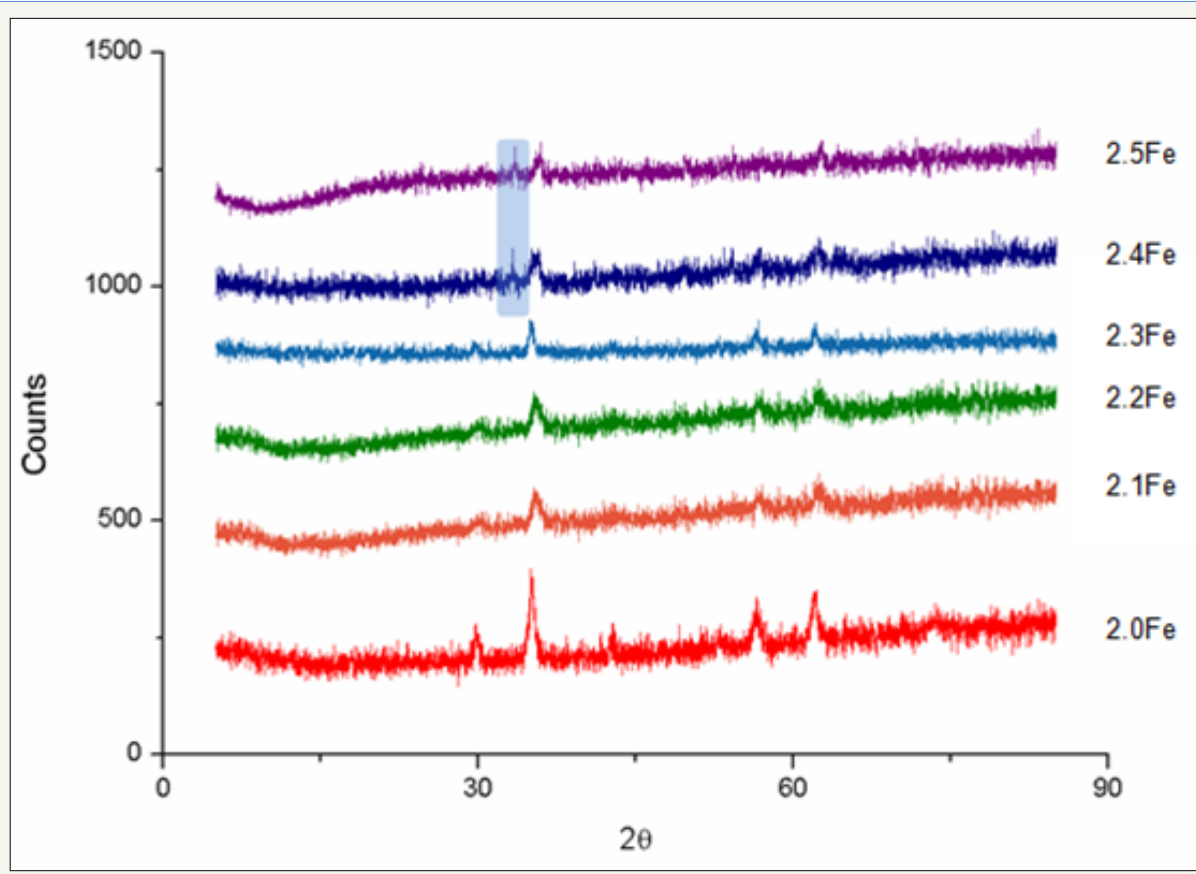

Figure 2: Comparison of X-ray diffraction patterns of zinc ferrite catalysts. 
EPR Spectroscopy: Electron paramagnetic resonance spectroscopy was performed on the zinc ferrite catalysts to look for changes to the electronic structure. The as-prepared catalysts displayed near-identical EPR spectra of an isotropic signal with a Lorentzian lineshape (Figure 3). The signal is characterized by the g-factor, the field-to-frequency ratio defined as $g=h v / \mu_{B} B$, where $h$ is Planck's constant, $v$ the microwave frequency ( $\mathrm{X}$-band, $\sim 9.8 \mathrm{GHz}$ ), $\mu_{B}$ is the Bohr magneton, and B the magnetic field. For extended solids such as zinc ferrite, the resonant field position-the crossing point in these derivative spectra-is not exclusively a function of the interaction of unpaired electrons with the magnetic field-the Zeeman interaction-but has contributions from the many spin-spin interactions within the material [30]. In this situation, the resonant field position is denoted by an effective $g$-value, $g_{\text {eff }}$ for the material, which is not wholly diagnostic of the electronic structure. More useful in the analysis of ternary oxides is the line width, which is defined as the distance between the positive and negative peaks of the derivative spectrum, $\Delta \mathrm{Bpp}$, in units of magnetic field (mT). Here, there is small albeit significant trend in $\Delta \mathrm{Bpp}$ for the prereaction catalysts, with line width of $19 \mathrm{mT}$ for $2.0 \mathrm{Fe}$ compared to $26 \mathrm{mT}$ for $2.5 \mathrm{Fe}$. This trend is not incremental across the series and due to the small variations in packing of the quartz tube and in homogeneity from the sample dilution.

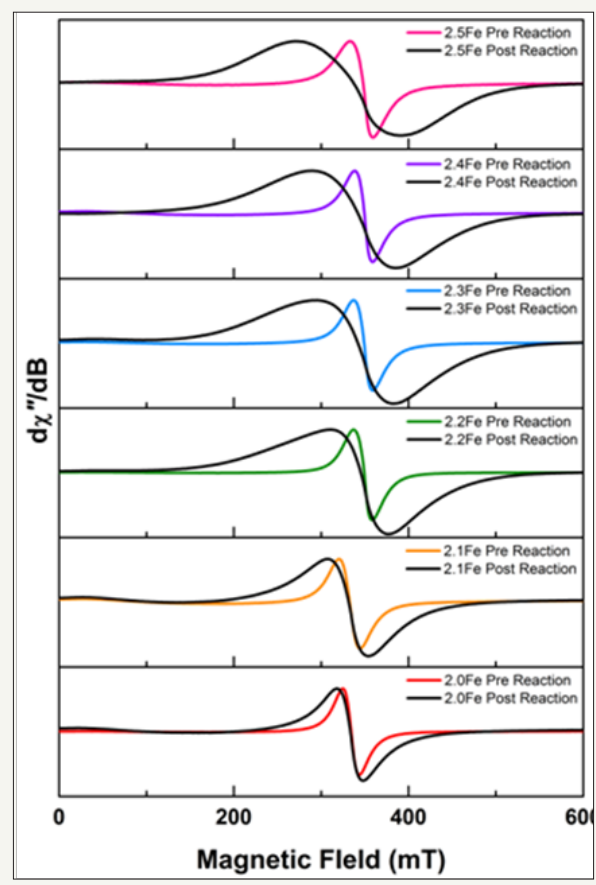

Figure 3: Overlay of the X-band EPR spectra for pre- and post-reaction ferrite catalysts normalised to the peak height of the derivative.
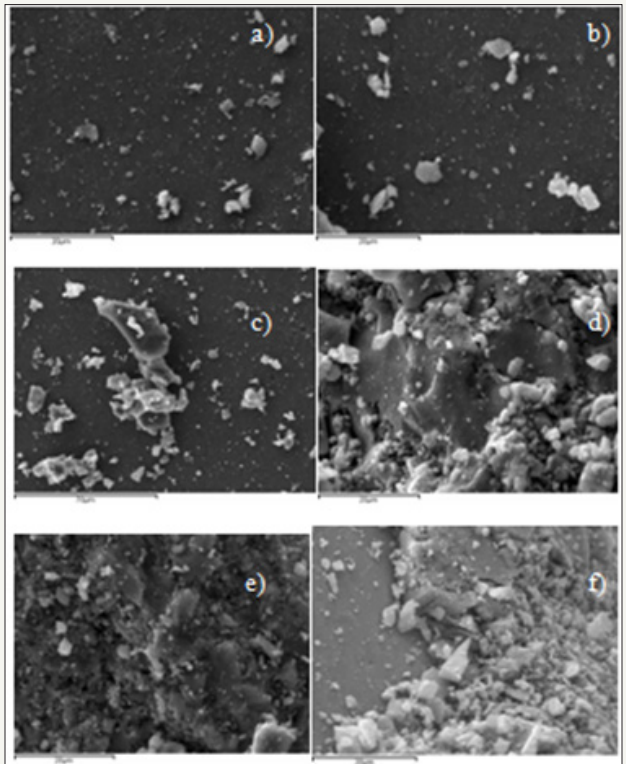

Figure 4: $\mathrm{SEM}$ images of ferrite catalysts a) $\mathrm{ZnFe}_{2} \mathrm{O}_{4}$ b) $\mathrm{Zn}_{0.9} \mathrm{Fe}_{2.1} \mathrm{O}_{4}$ c) $\mathrm{Zn}_{0.8} \mathrm{Fe}_{2.2} \mathrm{O}_{4}$ d) $\mathrm{Zn}_{0.7} \mathrm{Fe}_{2.3} \mathrm{O}_{4}$ e) $\mathrm{Zn}_{0.6} \mathrm{Fe}_{2.4} \mathrm{O}_{4}$ f) $\mathrm{Zn}_{0.5} \mathrm{Fe}_{2.5} \mathrm{O}_{4}$. 
SEM imaging: SEM images of the fresh catalysts Figure 4 shows the presence of a number of surface structures on each of the ferrites. These structures are of irregular shape and size but all appear to be $<10 \mu \mathrm{m}$ in diameter. As the Fe: $\mathrm{Zn}$ ratio of the catalyst was increased there was an increase in the presence of these structures. There also appears to be a change in the texture of the catalyst surface itself, which is quite smooth and featureless in the stoichiometric catalyst but becomes more rough and uneven as the Fe: $\mathrm{Zn}$ ratio is increased

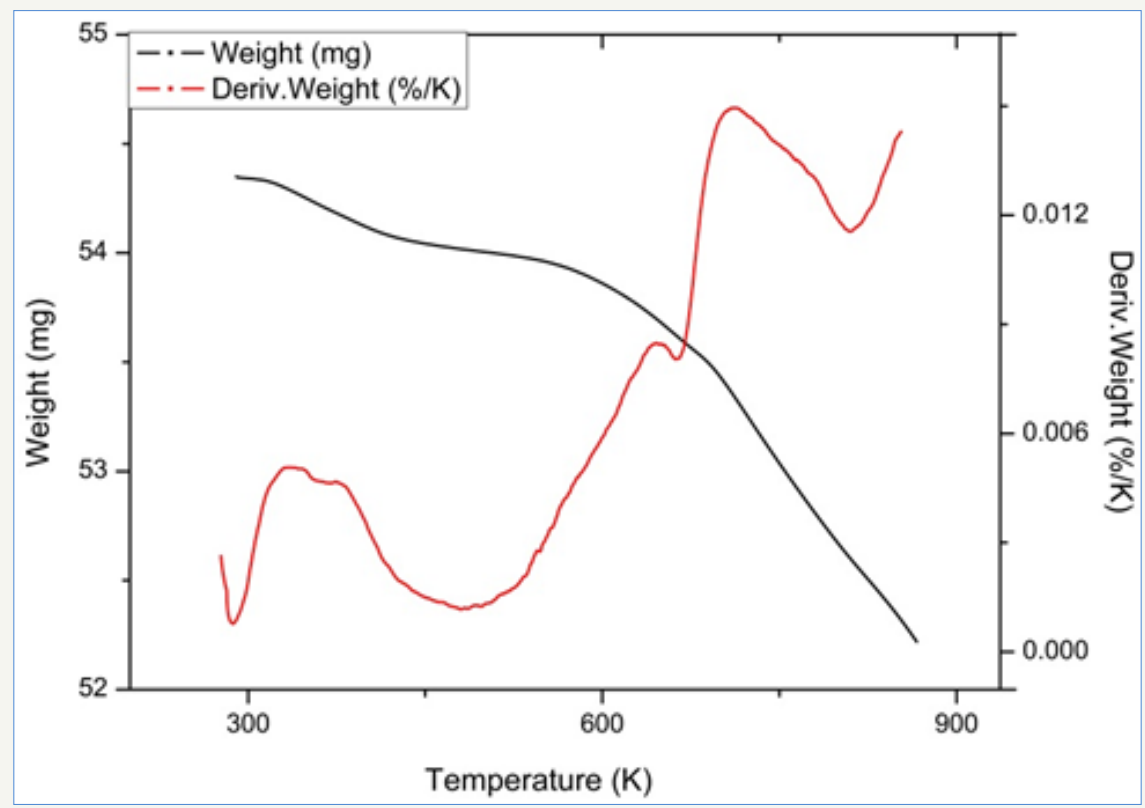

Figure 5: TPR profile of $2.0 \mathrm{Fe}$ catalyst.

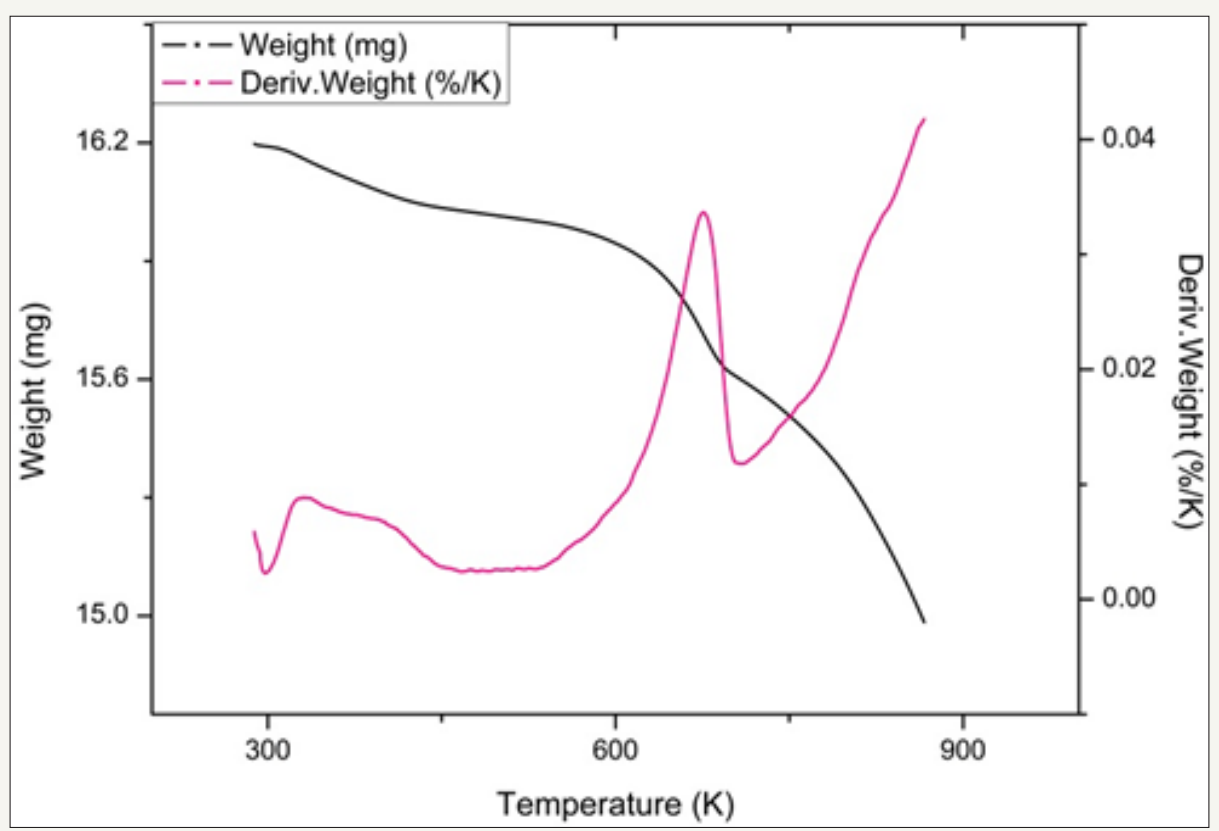

Figure 6: TPR profile of $2.5 \mathrm{Fe}$ catalyst.

Temperature programmed reduction : Figures 5 and 6 show the TPR the TPR profiles obtained for catalysts $2.0 \mathrm{Fe}$ and $2.5 \mathrm{Fe}$, TPR profiles for the remaining catalysts $(2.1 \mathrm{Fe}, 2.2 \mathrm{Fe}, 2.2 \mathrm{Fe}$ and $2.3 \mathrm{Fe}$ ) are available in the Supplementary Information. Catalysts 2.0Fe and 2.1Fe showed 3 distinct phases of weight loss at $\sim 370 \mathrm{~K}$, $\sim 670 \mathrm{~K}$ and $\sim 685 \mathrm{~K}$. The weight loss at $\sim 370 \mathrm{~K}$ was attributed to loss of adsorbed water from the catalyst surface, this was confirmed by mass spectrometry data collected during the reduction. The remaining two weight losses were attributed to reduction of $\mathrm{Fe}^{3+}$ to $\mathrm{Fe}^{2+}$ Catalysts $2.2 \mathrm{Fe}, 2.3 \mathrm{Fe}, 2.4 \mathrm{Fe}$ and $2.5 \mathrm{Fe}$ also showed loss of adsorbed water at $\sim 370 \mathrm{~K}$ and a further weight loss event at $\sim 670 \mathrm{~K}$, however there is no evidence of the third weight loss event at $\sim 685 \mathrm{~K}$. 
Figure 7 shows the percentage weight loss, for each of the zinc ferrite catalysts, with increasing temperature. The graph has been normalised so as to exclude any weight loss before $450 \mathrm{~K}$ as this was attributed to loss of physisorbed water and is not related to reduction of the ferrite itself. It can be seen that overall percentage weught loss increases with increased Fe:Zn ratio, with catalyst $2.5 \mathrm{Fe}$ showing the highest weight loss by the end of the experiment, $\sim 6 \%$.

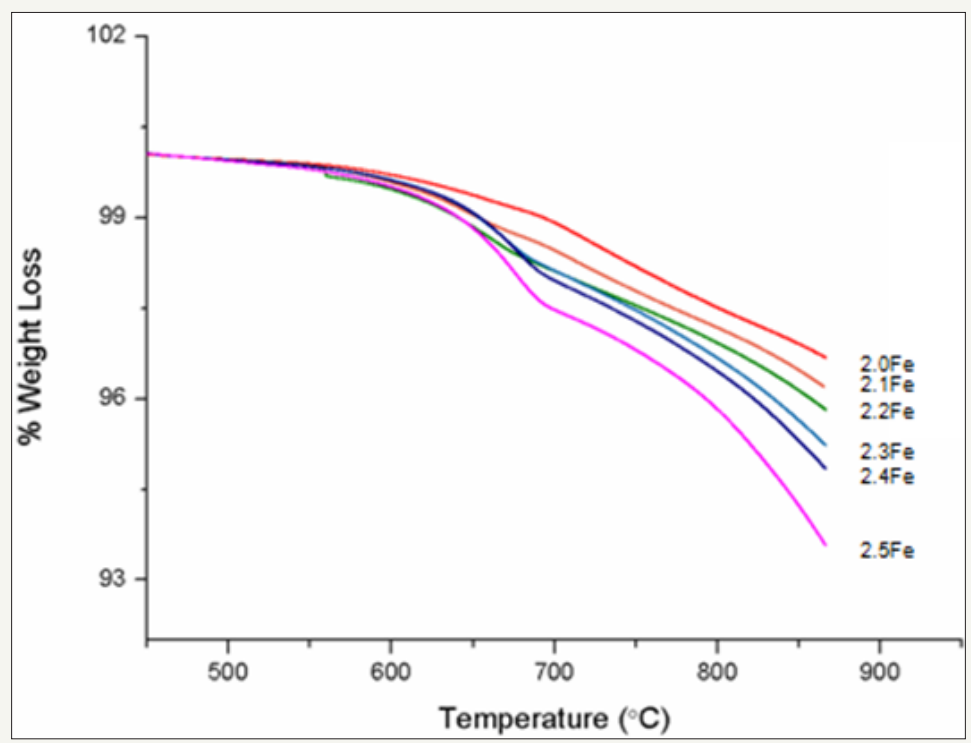

Figure 7: Percentage weight loss with temperature for zinc ferrite catalysts.

Oxidative Dehydrogenation of 1-Butene over Metal Ferrites: Figure 8 shows the 1-butene conversion throughout the oxidative dehydrogenation reactions for the zinc ferrite catalysts tested. With the exception of $2.4 \mathrm{Fe}$, a decrease in conversion, over the course of the reaction, was observed for all catalysts tested. Conversion was shown to decrease with increasing catalyst Fe: $\mathrm{Zn}$ ratio, with catalysts $\mathrm{Zn}_{0.5} \mathrm{Fe}_{2.5} \mathrm{O}_{4}$ performing the worst and the stoichiometric zinc ferrite performing best. Table 5 shows the deactivation constants, $\mathrm{k}_{\mathrm{d}}$, calculated for each of the zinc ferrite catalysts tested for 1-butene ODH. The highest $\mathrm{k}_{\mathrm{d}}$ was calculated for the catalyst $2.1 \mathrm{Fe}$ and the lowest was for catalyst $2.4 \mathrm{Fe}$, however no direct correlation was observed between kd and increased Fe: Zn ratio.
Table 5: Deactivation constants for ODH of 1-butene over zinc ferrites.

\begin{tabular}{|c|c|}
\hline Catalyst & $\mathbf{k}_{\mathbf{d}}$ \\
\hline $2.0 \mathrm{Fe}$ & 0.0107 \\
\hline $2.1 \mathrm{Fe}$ & 0.0126 \\
\hline $2.2 \mathrm{Fe}$ & 0.0047 \\
\hline $2.3 \mathrm{Fe}$ & 0.0062 \\
\hline $2.4 \mathrm{Fe}$ & 0.0002 \\
\hline $2.5 \mathrm{Fe}$ & 0.0118 \\
\hline
\end{tabular}

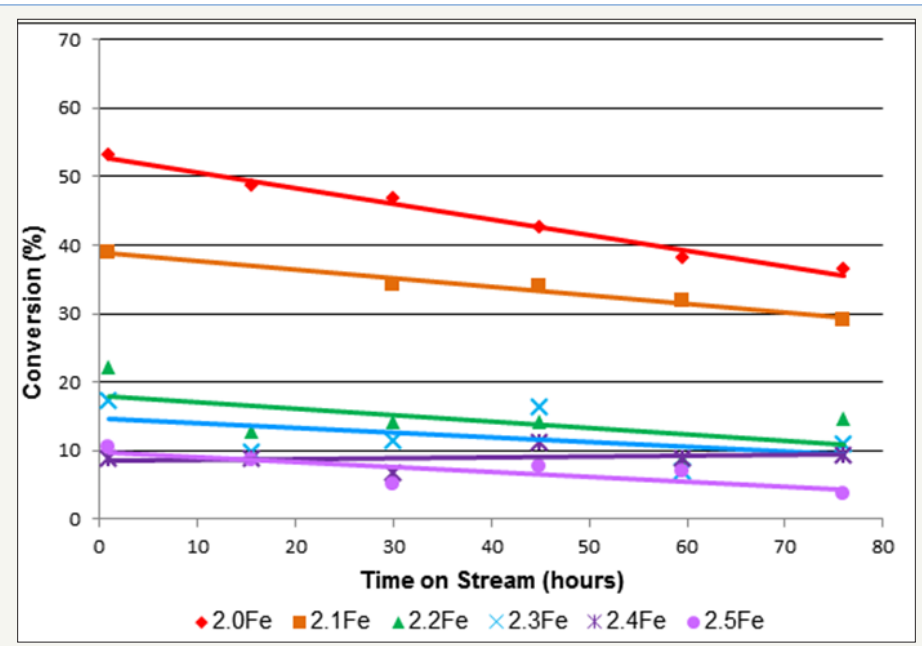

Figure 8: 1-Butene conversion as a function of time on stream for 1-butene ODH over zinc ferrite catalysts (limited number of points shown for clarity). 
1, 3-Butadiene was the major reaction product for each of the catalysts tested although the catalysts also were active for butene isomerisation. Figure 9 clearly shows that upon increasing the Fe: $\mathrm{Zn}$ ratio of the catalyst, above that of the stoichiometric catalyst, there was a notable decrease in 1, 3-butadiene yield. Table 6 shows the 1, 3-butadiene selectivity's observed for each catalyst at 30 and $75 \mathrm{~h}$. The results show a selectivity of $98.9 \%$ for the stoichiometric zinc ferrite after $30 \mathrm{~h}$, which was virtually the same after $75 \mathrm{~h}$.
Selectivity after $30 \mathrm{~h}$ was shown to decrease with increasing Fe: $\mathrm{Zn}$ ratio, with catalyst $2.4 \mathrm{Fe}$ showing the lowest selectivity (48.7\%) after $30 \mathrm{~h}$. It can also be observed that in all of the catalysts with an Fe: $\mathrm{Zn}$ ratio above that of the stoichiometric catalyst there was a significant decrease in selectivity between the 30 and 75 hour samples. This decrease in selectivity was most pronounced in the $2.5 \mathrm{Fe}$ catalyst where selectivity after $75 \mathrm{~h}$ was only $17.3 \%$.

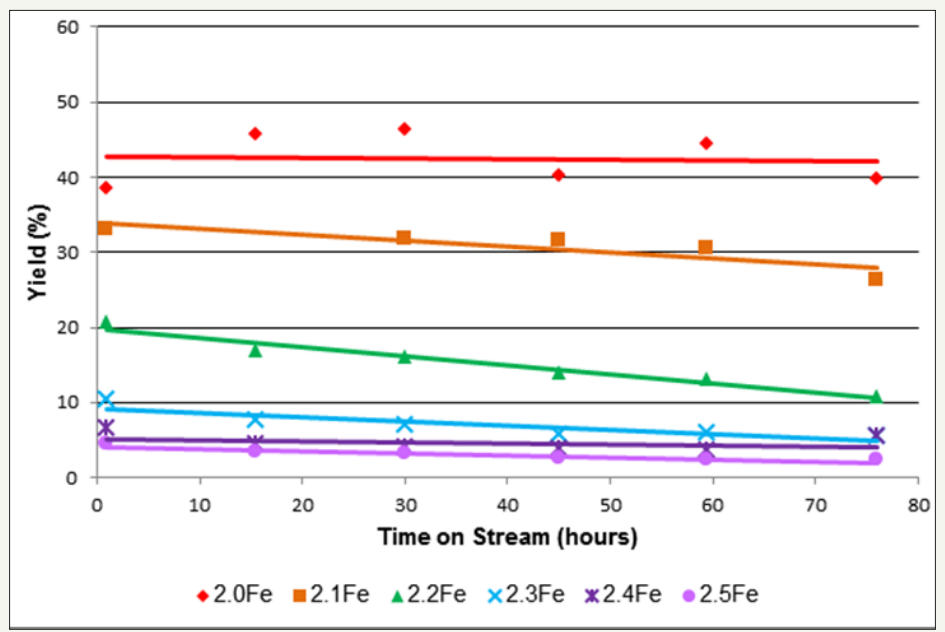

Figure 9: 1, 3-Butadiene yield as a function of time on stream for 1-butene ODH over zinc ferrite catalysts (limited number of points shown for clarity).

Table 6: 1, 3-Butadiene selectivity for 1-butene ODH over zinc ferrite catalysts at 30 and $75 \mathrm{~h}$.

\begin{tabular}{|c|c|c|}
\hline \multirow{2}{*}{ Catalyst } & \multicolumn{2}{|c|}{$\mathbf{1 , 3 - B u t a d i e n e ~ S e l e c t i v i t y ~ ( \% ) ~}$} \\
\cline { 2 - 4 } & $\mathbf{3 0 h}$ & $\mathbf{7 5 h}$ \\
\hline $2.0 \mathrm{Fe}$ & 98.9 & 99.2 \\
\hline $2.1 \mathrm{Fe}$ & 93.1 & 84.3 \\
\hline $2.2 \mathrm{Fe}$ & 94.3 & 57.6 \\
\hline $2.3 \mathrm{Fe}$ & 61.4 & 46.1 \\
\hline $2.4 \mathrm{Fe}$ & 48.7 & 38.1 \\
\hline $2.5 \mathrm{Fe}$ & 63.5 & 17.3 \\
\hline
\end{tabular}

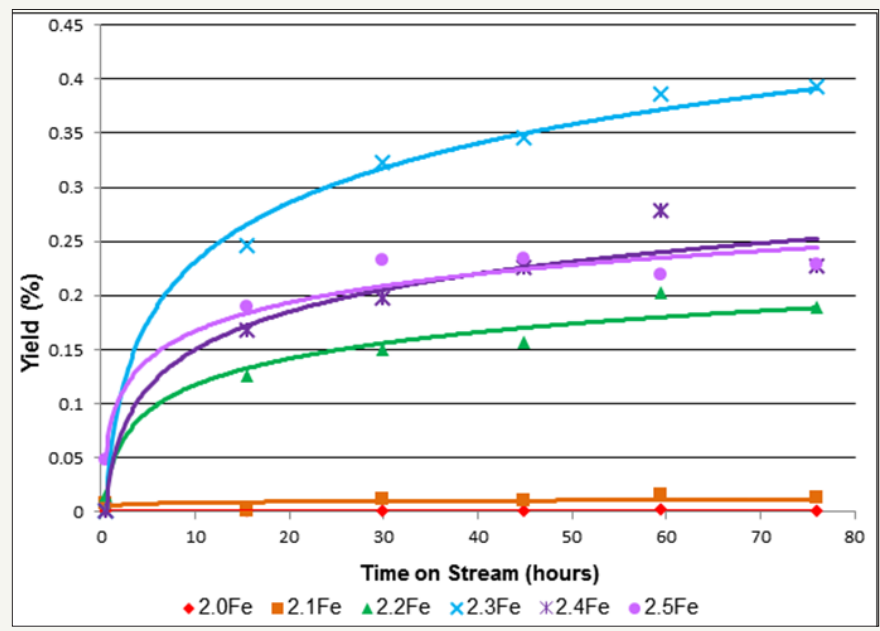

Figure 10: Butane yield as a function of time on stream for 1-butene ODH over zinc ferrite catalysts (limited number of points shown for clarity). 
When the oxidative dehydrogenation of 1-butene was carried out over the stoichiometric catalyst, $2.0 \mathrm{Fe}$, the yield of butane was less than $0.001 \%$ and selectivity less than $0.1 \%$ making butane a minor reaction product. However as the Fe: $\mathrm{Zn}$ ratio of the zinc ferrites was increased there was a marked increase in butane yield and selectivity (Figure 10 and Table 7). The ferrite with the highest Fe: $\mathrm{Zn}$ ratio, $\mathrm{Zn}_{0.5} \mathrm{Fe}_{2.5} \mathrm{O}_{4}$, showed the highest butane selectivity and yield, $\sim 9 \%$ and $\sim 0.4 \%$ respectively, after $75 \mathrm{~h}$. Butane yield is shown to increase with time on stream for all of the catalysts tested, Figure 10 .

Table 7: Butane selectivities for 1-butene ODH over zinc ferrite catalysts at 30 and $75 \mathrm{~h}$.

\begin{tabular}{|c|c|c|}
\hline \multirow{2}{*}{ Catalyst } & \multicolumn{2}{|c|}{ Butane Selectivity (\%) } \\
\hline & $30 \mathrm{~h}$ & $75 \mathrm{~h}$ \\
\hline $2.0 \mathrm{Fe}$ & 0.0 & 0.0 \\
\hline $2.1 \mathrm{Fe}$ & 0.0 & 0.1 \\
\hline $2.2 \mathrm{Fe}$ & 0.8 & 1.1 \\
\hline $2.3 \mathrm{Fe}$ & 2.9 & 2.0 \\
\hline $2.4 \mathrm{Fe}$ & 2.3 & 2.1 \\
\hline $2.5 \mathrm{Fe}$ & 4.6 & 7.1 \\
\hline
\end{tabular}

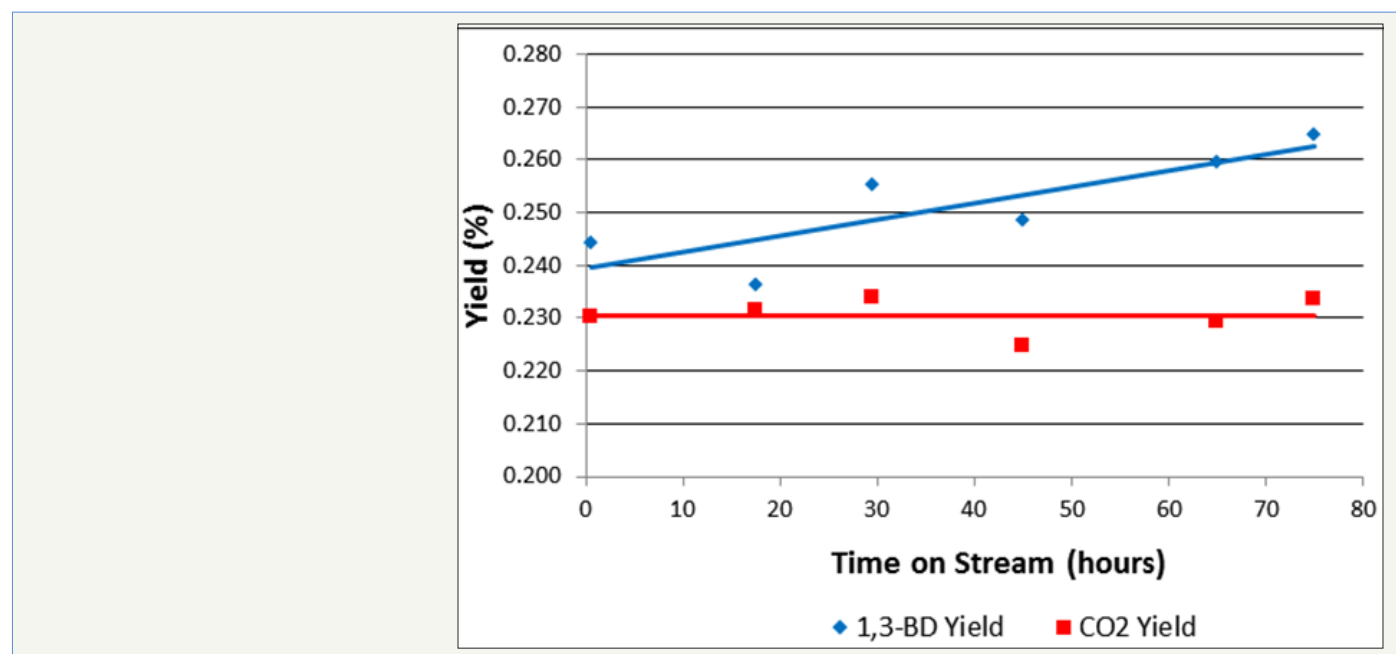

Figure 11: 1, 3-Butadiene (1,3-BD) and carbon dioxide yield as a function of time on stream for 1-butene ODH over an a/y $\mathrm{Fe}_{2} \mathrm{O}_{3}$ catalyst [22].

Some isomerisation to produce cis- and trans-2-butene was observed in each reaction. Typically less than $10 \%$ of the 1-butene reactant feed was isomerised to cis- and trans-2-butene at any given point during the time on stream. As well as the main reaction products described above, there were also a variety of minor reaction products produced by isomerisation reactions and cracking namely isobutene, propane, ethane and methane, each with a selectivity of $<1 \%$ over the stoichiometric zinc ferrite catalyst. Methane, ethane and propane all showed minor increases in selectivity as the Fe: $\mathrm{Zn}$ ratio of the ferrite catalyst was increased. Conversion of 1-butene over an $\alpha / \gamma-\mathrm{Fe}_{2} \mathrm{O}_{3}$ catalyst was shown to be extremely low, $<1 \%$, with 1,3-butadiene and carbon dioxide the main products of the reaction, both had yields of around $\sim 0.2 \%$ throughout the time on stream (Figure 11).

\section{Post-Reaction Catalyst Characterisation}

\section{XPS}

XPS data from post reaction catalyst samples (Table 2) showed an increase in measured Fe: $\mathrm{Zn}$ ratio for both the stoichiometric and the $2.5 \mathrm{Fe}$ catalysts. The calculated atom percentages show that, for both catalysts, the percentage of both $\mathrm{Fe}^{3+}$ and $\mathrm{Zn}^{2+}$ decrease over the duration of the reaction whilst the percentage of $\mathrm{O}^{2-}$ measured at the surface increased.

\section{BET surface area}

Post-reaction catalyst surface area measurements, (Table 3), showed a significant decrease in catalyst surface area relative to pre- reaction as a result of sintering in the presence of steam [31]. Average pore diameter is increased post reaction but total pore volume changed very little, suggesting that smaller catalyst pores are closing in over the course of the reaction.

\section{Raman Spectroscopy}

Post reaction Raman spectra showed no observable changes to the catalysts, full results is available in the supplementary information (Figures 12-21).

\section{X-ray diffraction (XRD)}

Post reaction XRD patterns showed no changes in terms of peak position, relative intensity or appearance of additional peaks. It was noted however that the post reaction XRD patterns showed slightly better defined peaks and a slightly reduced amorphous background, indicating an increased crystallinity and particle size. Full results for post-reaction XRD are available in the supplementary information (Figures 22-27). 


\section{Supplementary Information}

\section{Temperature Programmed Reduction}

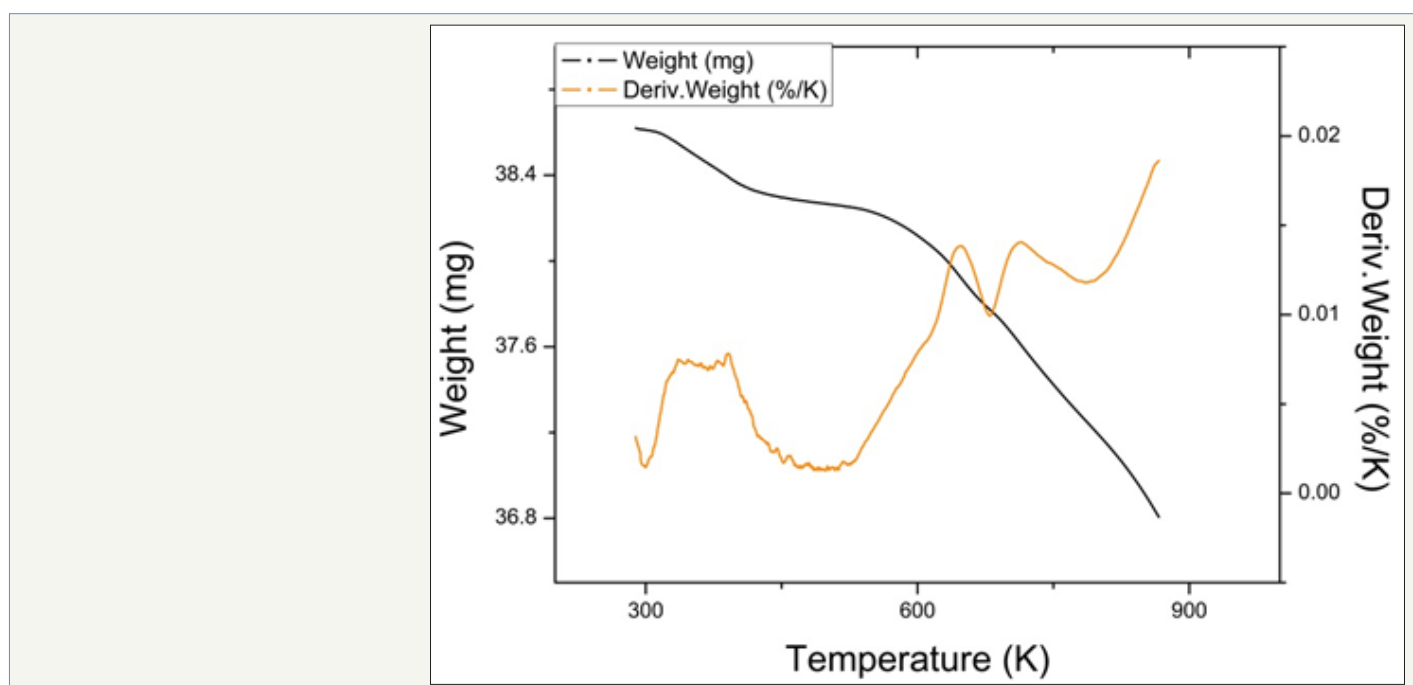

Figure 12: TPR profiles for catalyst $2.1 \mathrm{Fe}$.

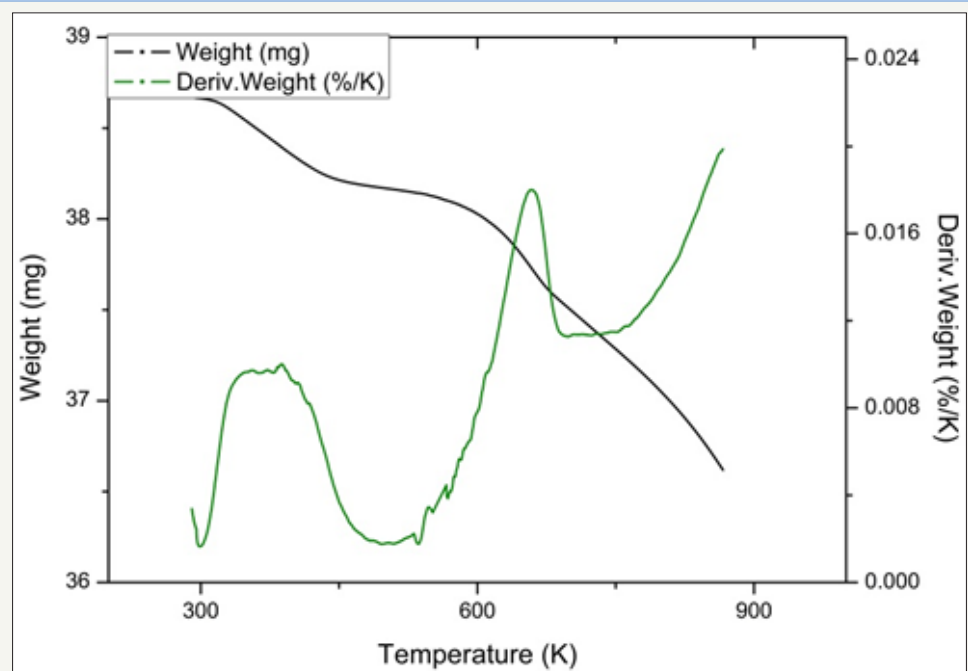

Figure 13: TPR profiles for catalyst $2.2 \mathrm{Fe}$.

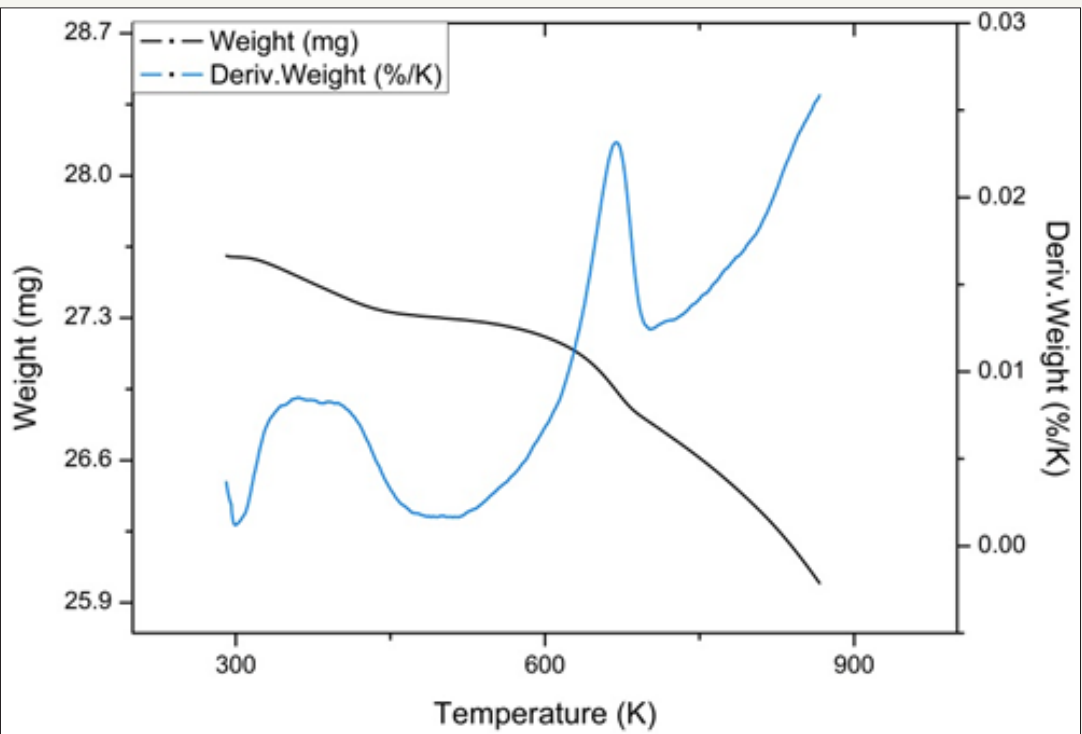

Figure 14: TPR profiles for catalyst $2.3 \mathrm{Fe}$. 


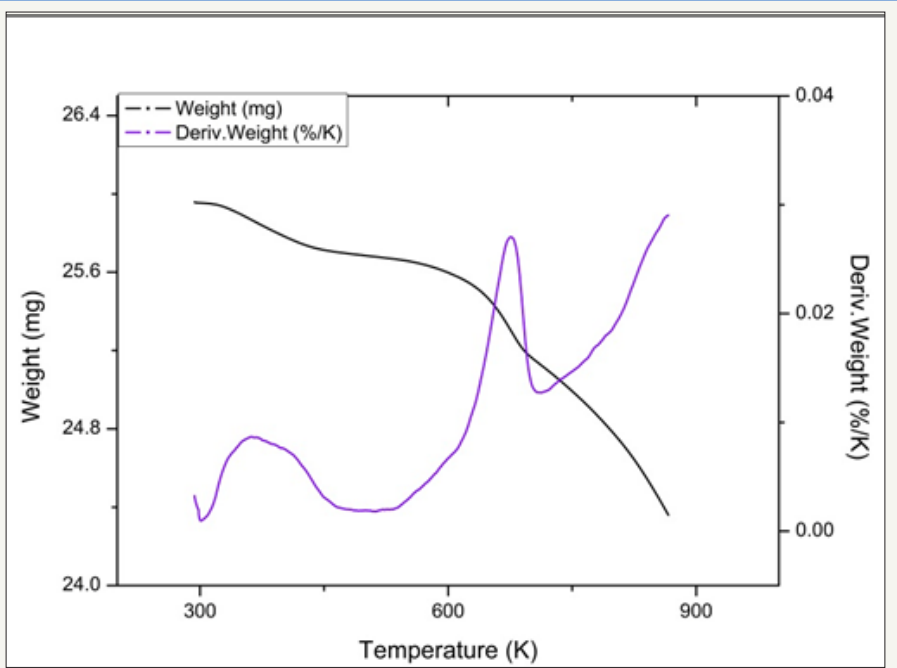

Figure 15: TPR profiles for catalyst $2.4 \mathrm{Fe}$.

\section{Post Reaction Raman}

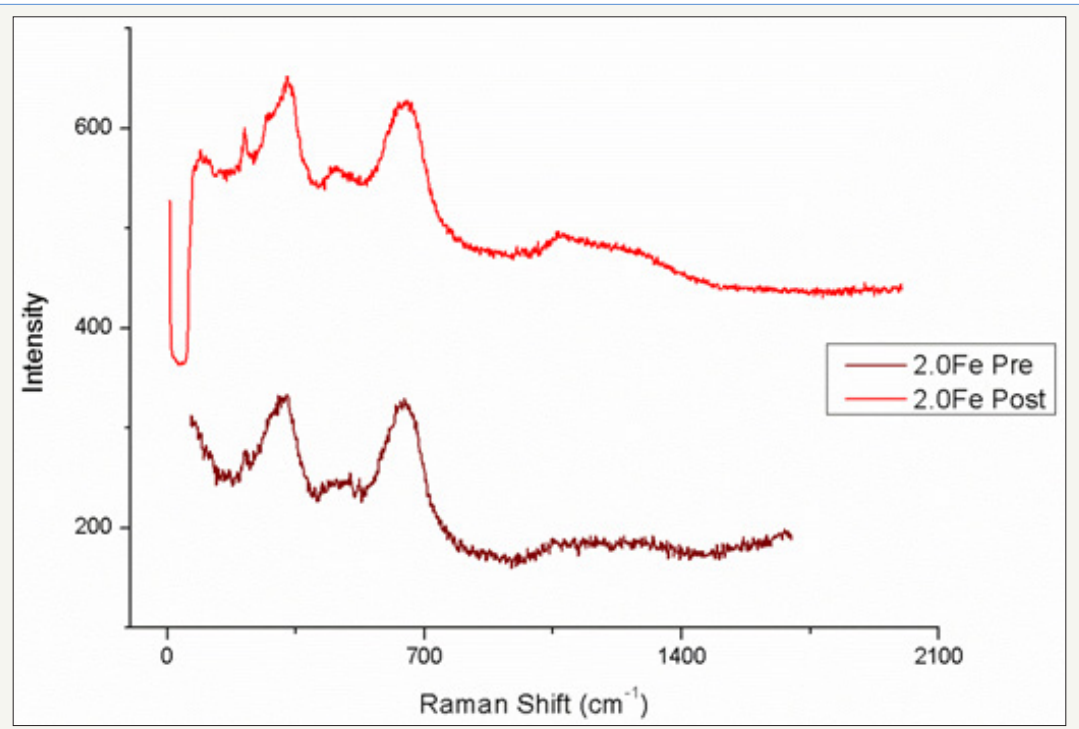

Figure 16: Comparison of pre and post reaction ferrite Raman spectra for catalyst 2.0Fe.

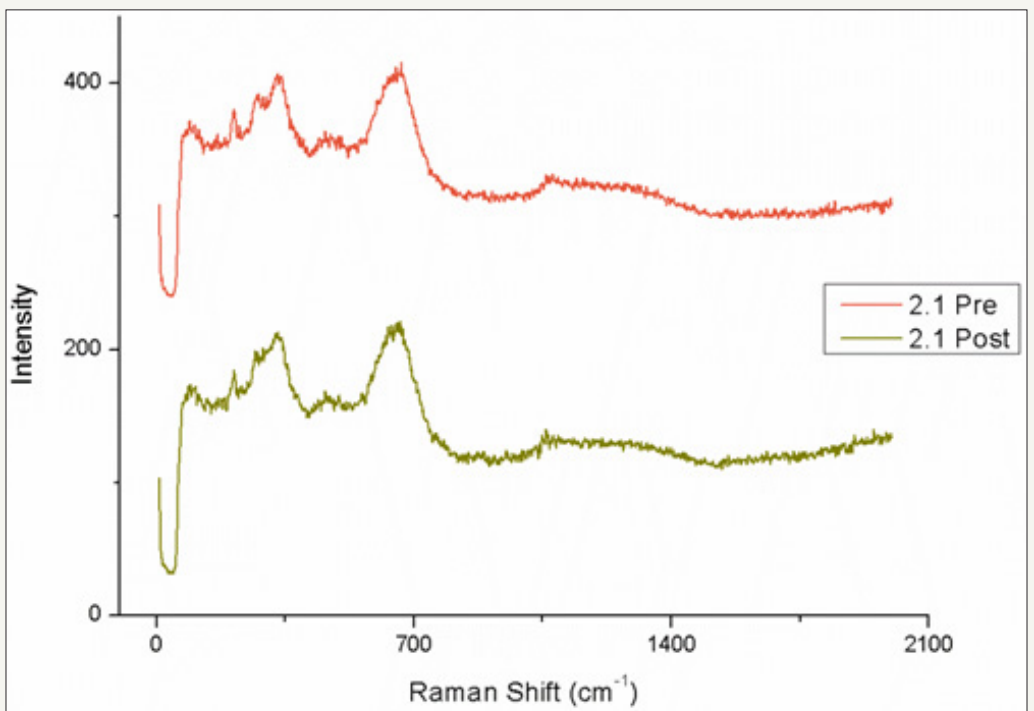

Figure 17: Comparison of pre and post reaction ferrite Raman spectra for catalyst $2.1 \mathrm{Fe}$. 


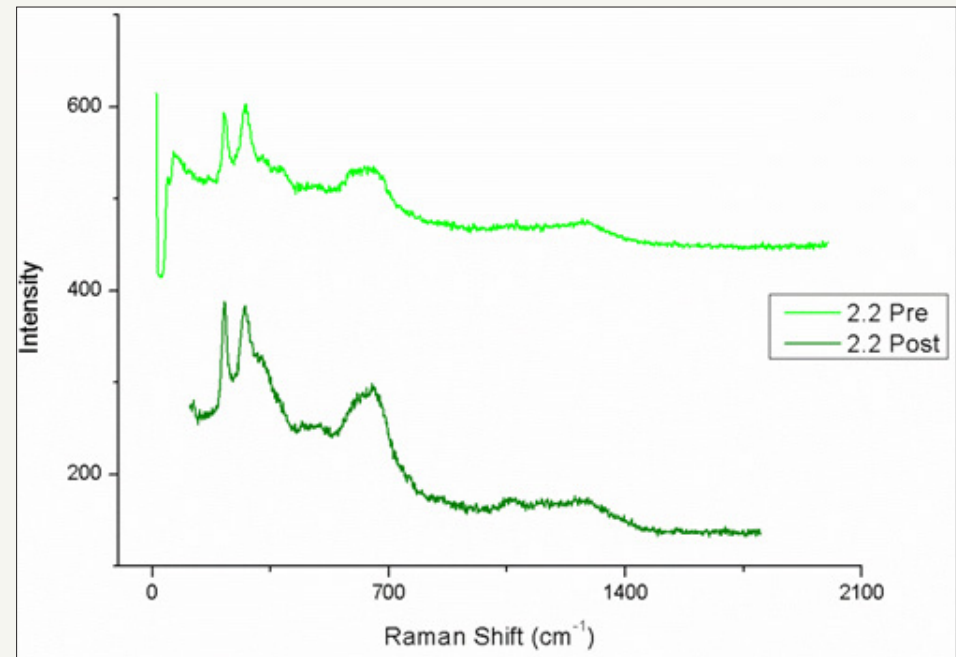

Figure 18: Comparison of pre and post reaction ferrite Raman spectra for catalyst 2.2Fe.

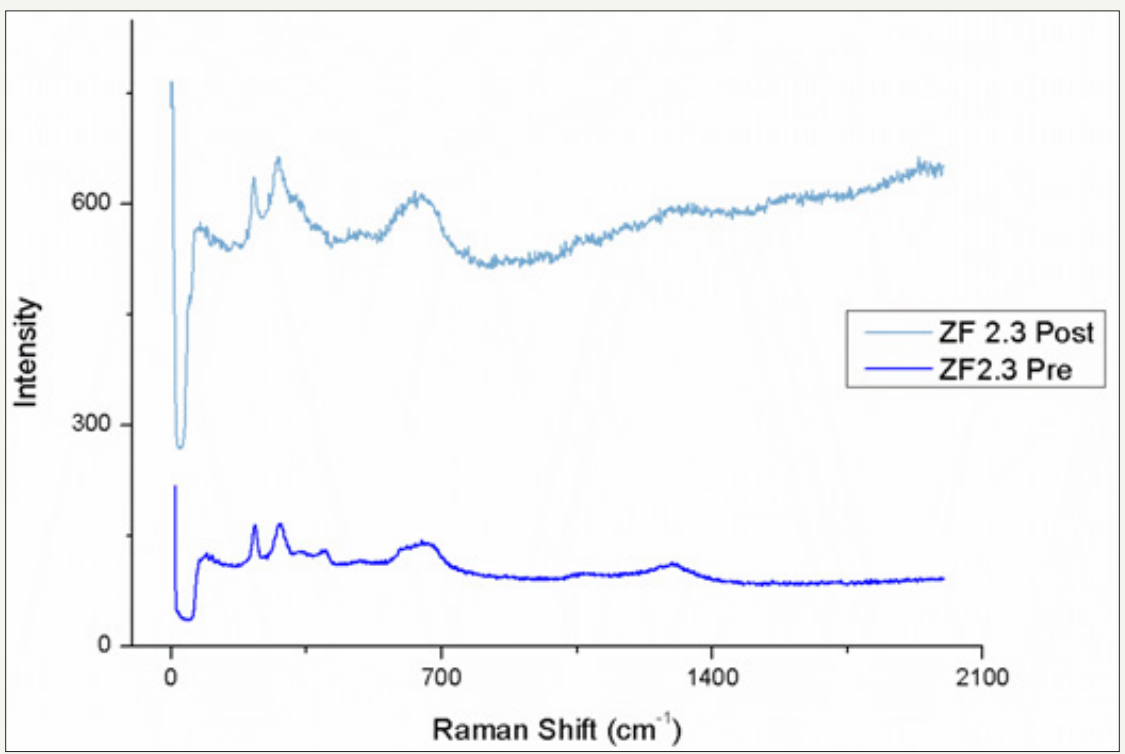

Figure 19: Comparison of pre and post reaction ferrite Raman spectra for catalyst $2.3 \mathrm{Fe}$.

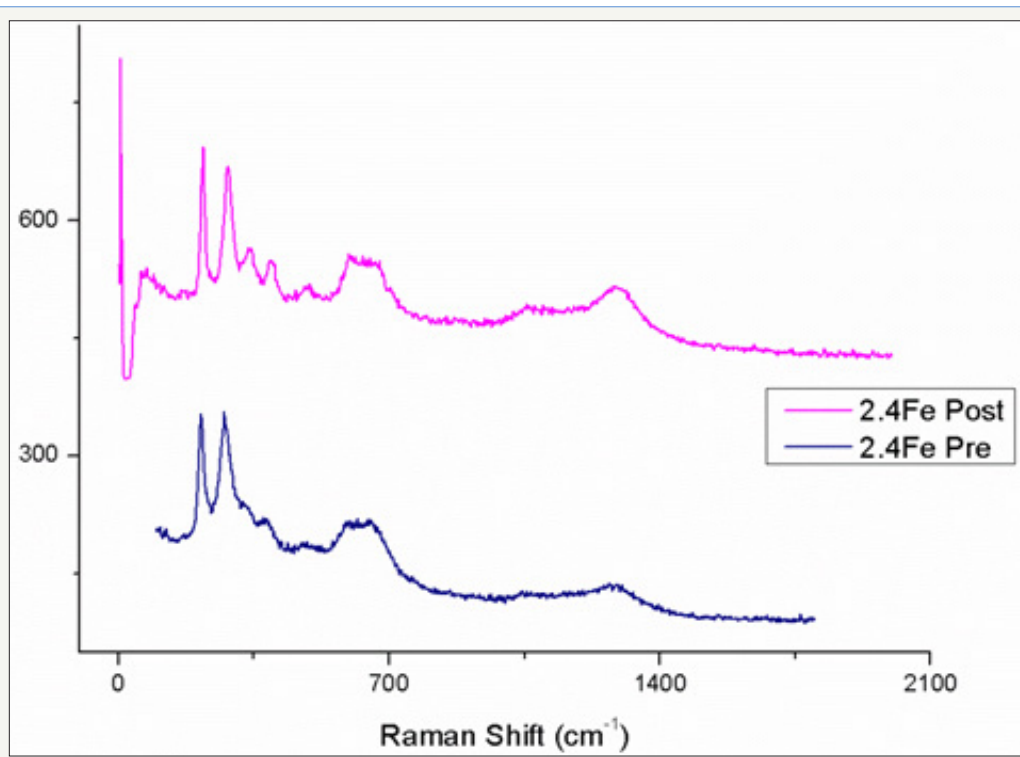

Figure 20: Comparison of pre and post reaction ferrite Raman spectra for catalyst $2.4 \mathrm{Fe}$. 


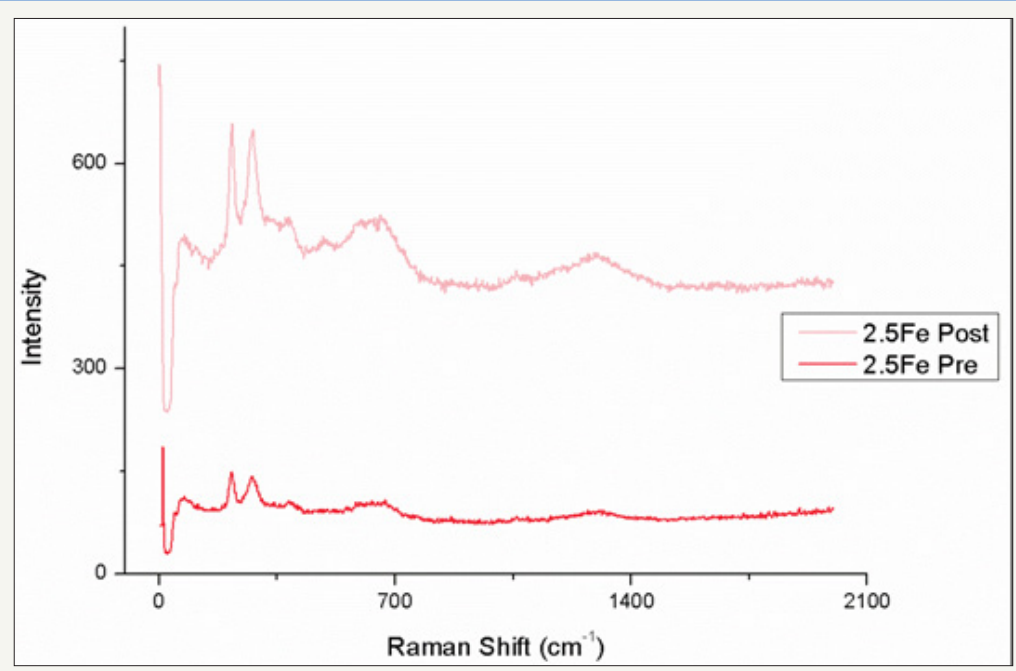

Figure 21: Comparison of pre and post reaction ferrite Raman spectra for catalyst $2.5 \mathrm{Fe}$.

\section{Post Reaction X-Ray Diffraction}

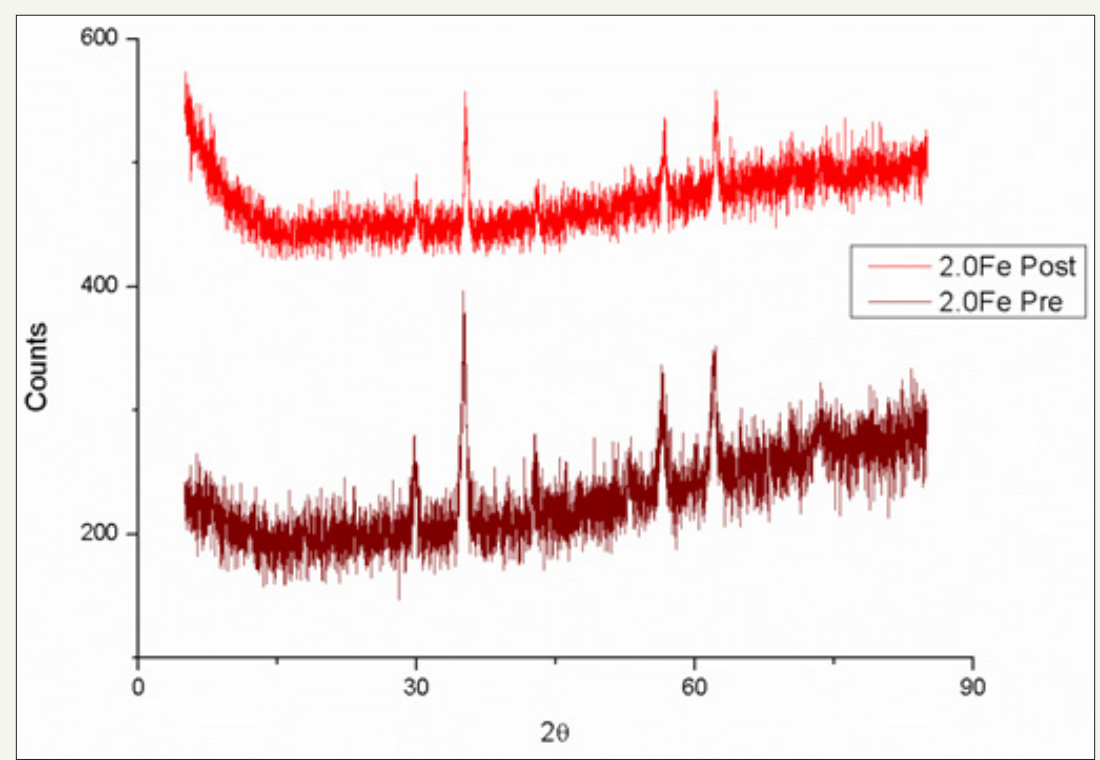

Figure 22: Comparison ofpre and post reaction ferrite XRD patterns for catalyst 2.0Fe.

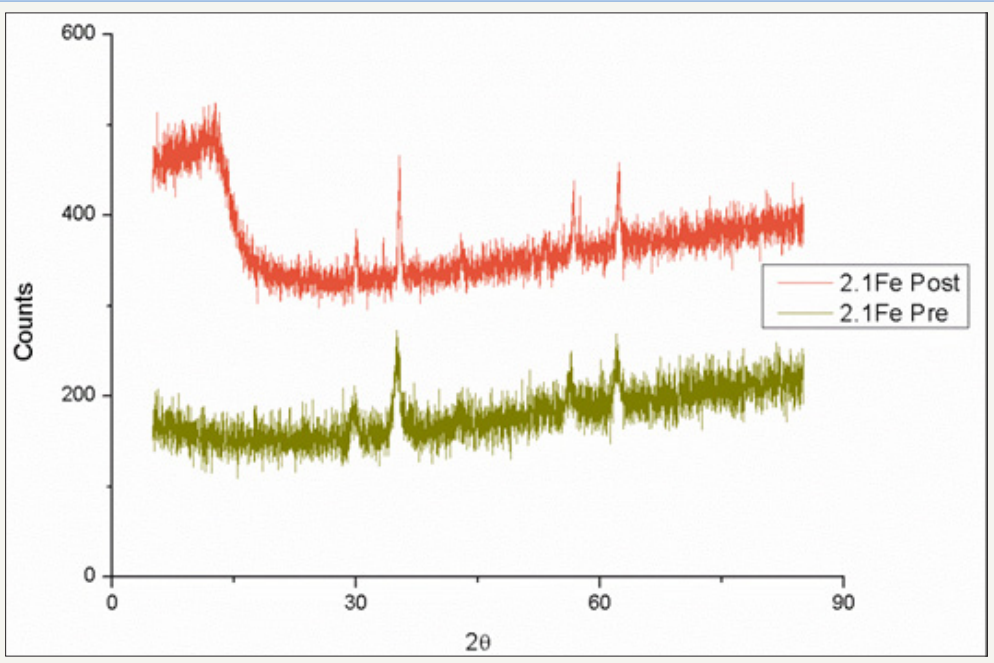

Figure 23: Comparison of pre and post reaction ferrite XRD patterns for catalyst $2.1 \mathrm{Fe}$. 


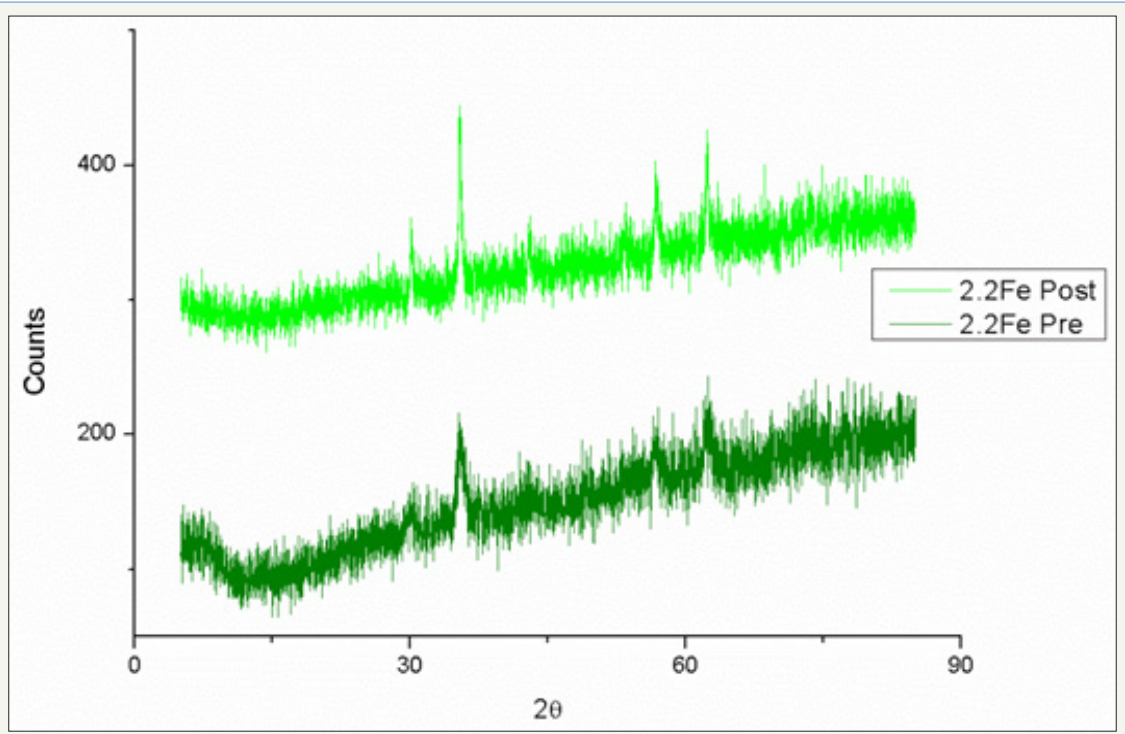

Figure 24: Comparison of pre and post reaction ferrite XRD patterns for catalyst $2.2 \mathrm{Fe}$.

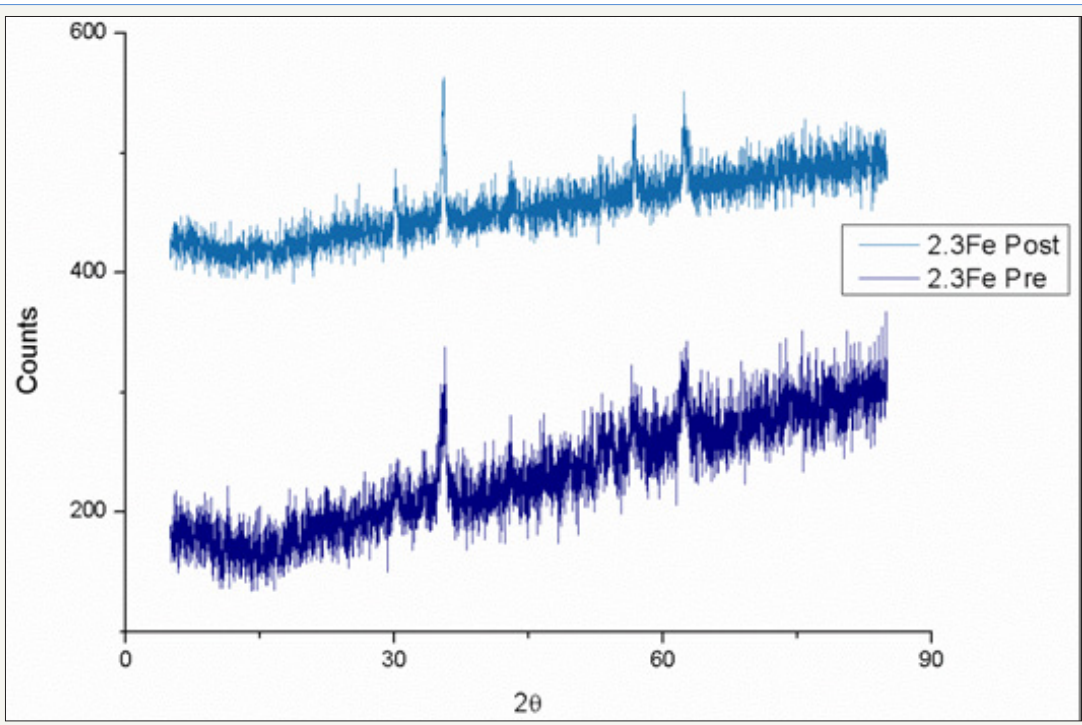

Figure 25: Comparison of pre and post reaction ferrite XRD patterns for catalyst $2.3 \mathrm{Fe}$.

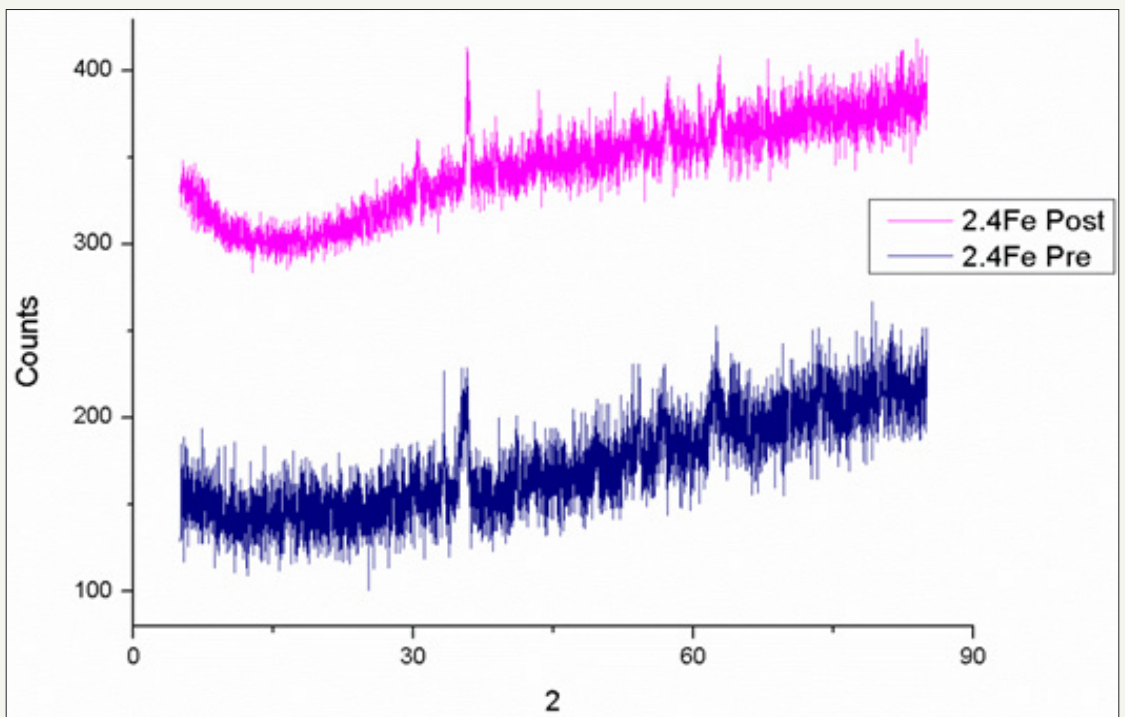

Figure 26: Comparison of pre and post reaction ferrite XRD patterns for catalyst $2.4 \mathrm{Fe}$. 


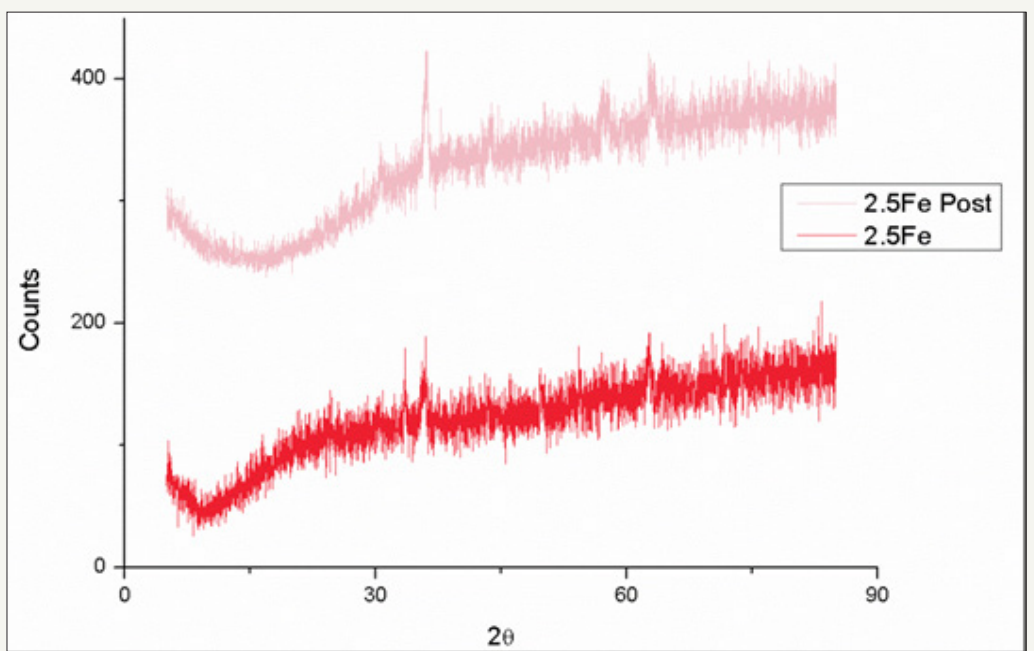

Figure 27: Comparison of pre and post reaction ferrite XRD patterns for catalyst $2.5 \mathrm{Fe}$.

\section{Electron paramagnetic spectroscopy (EPR)}

All of the post reaction catalysts were examined by EPR spectroscopy for comparison with pre-reaction samples, Figure 3. For all ferrite catalysts tested there was a noticeable peak broadening in the post reaction samples, diagnostic of a structural change in the spinel. The shift towards a normal spinel was greater in the higher Fe: $\mathrm{Zn}$ ratio catalysts.

\section{SEM}

Post reaction SEM was carried out on all of the ferrite samples and showed very little difference when compared to that of the fresh catalyst. Full results for post reaction SEM can be found in the supplementary information (Figure 28).

\section{Post Reaction SEM}

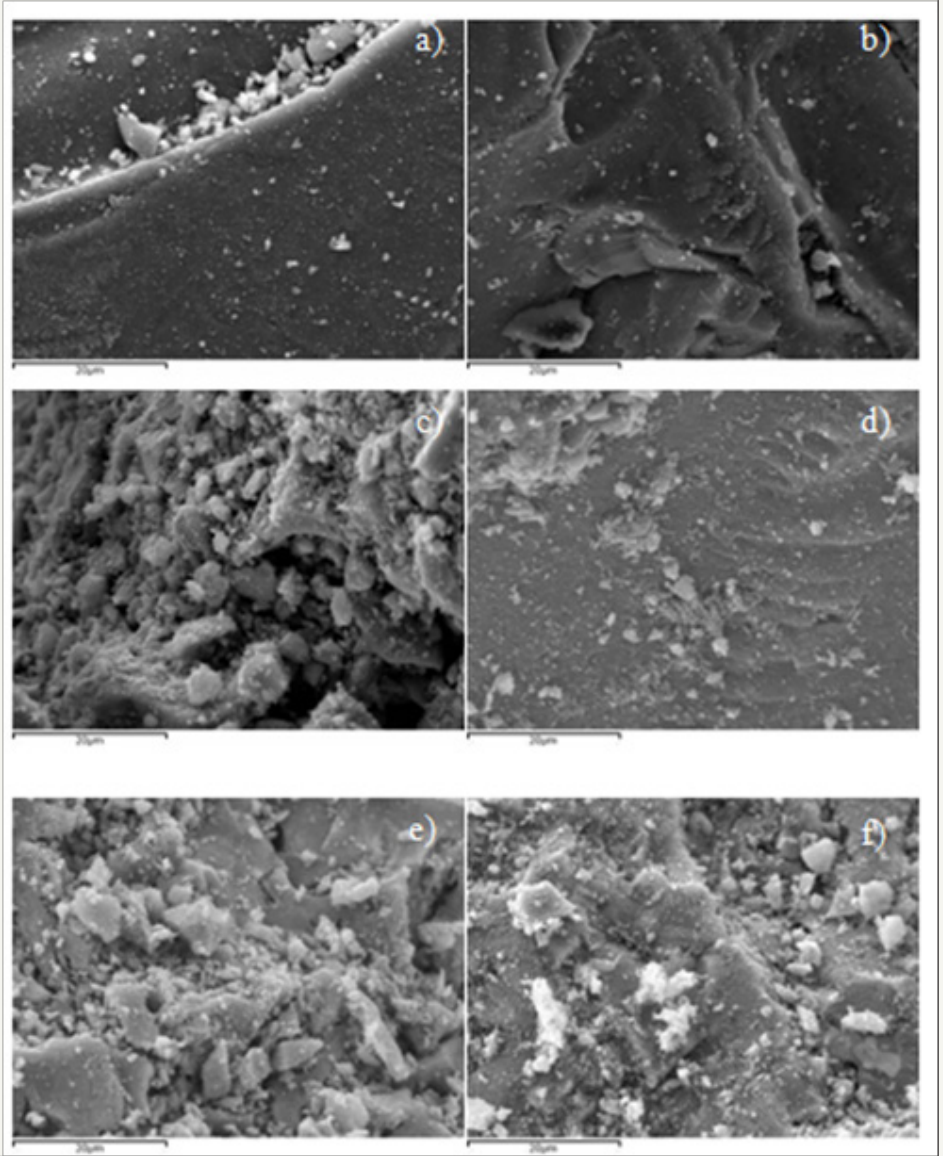

Figure 28: Post reaction SEM images of ferrite catalysts a) $\mathrm{ZnFe}_{2} \mathrm{O}_{4}$ b) $\mathrm{Zn}_{0.9} \mathrm{Fe}_{2} \cdot 1 \mathrm{O}_{4}$ c) $\mathrm{Zn}_{0.8} \mathrm{Fe}_{2} \cdot 2 \mathrm{O}_{4}$ d) $\mathrm{Zn}_{0.7} \mathrm{Fe}_{2} \cdot 3 \mathrm{O}_{4}$ e) $\mathrm{Zn}_{0.6} \mathrm{Fe}_{2} \cdot \mathrm{O}_{4}$ f) $\mathrm{Zn}_{0.5} \mathrm{Fe}_{2} \cdot 5 \mathrm{O}_{4}$. 


\section{Thermogravimetric analysis (TGA)}

TGA was performed on all of the post reaction catalyst samples in the presence of oxygen. For all catalysts a total weight loss of $<1 \%$ was observed over the temperature range $290 \mathrm{~K}$ to $1265 \mathrm{~K}$. The weight loss recorded occurred over the temperature range $303 \mathrm{~K}$ to $473 \mathrm{~K}$ and was associated with the loss of adsorbed water from the catalyst. Full results for post-reaction TGA are available in the supplementary information (Figures 29-34).

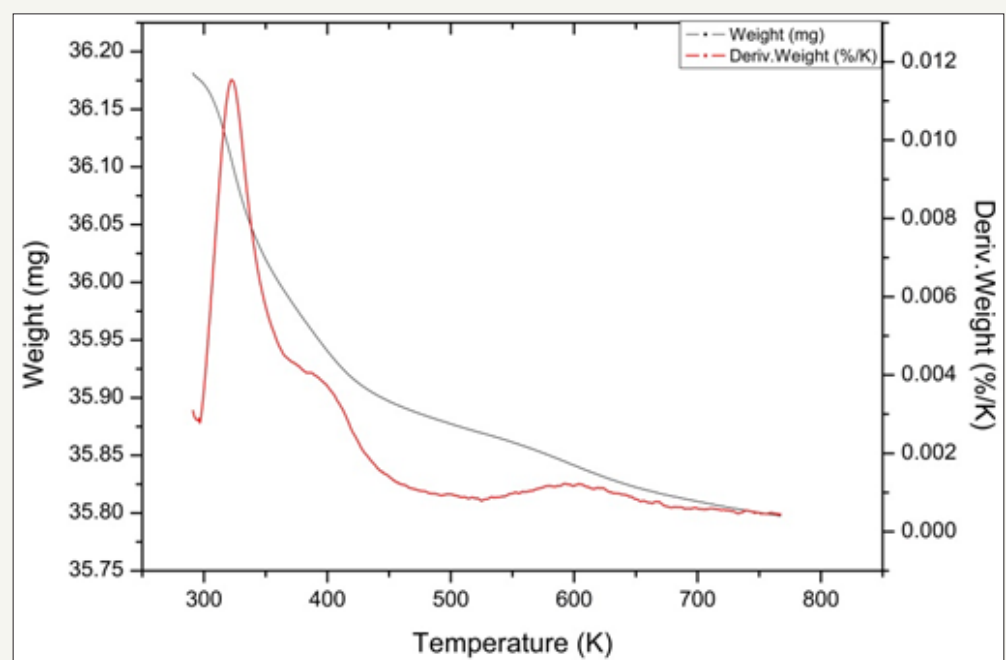

Figure 29: Post reaction TGA results for catalyst $2.0 \mathrm{Fe}$.

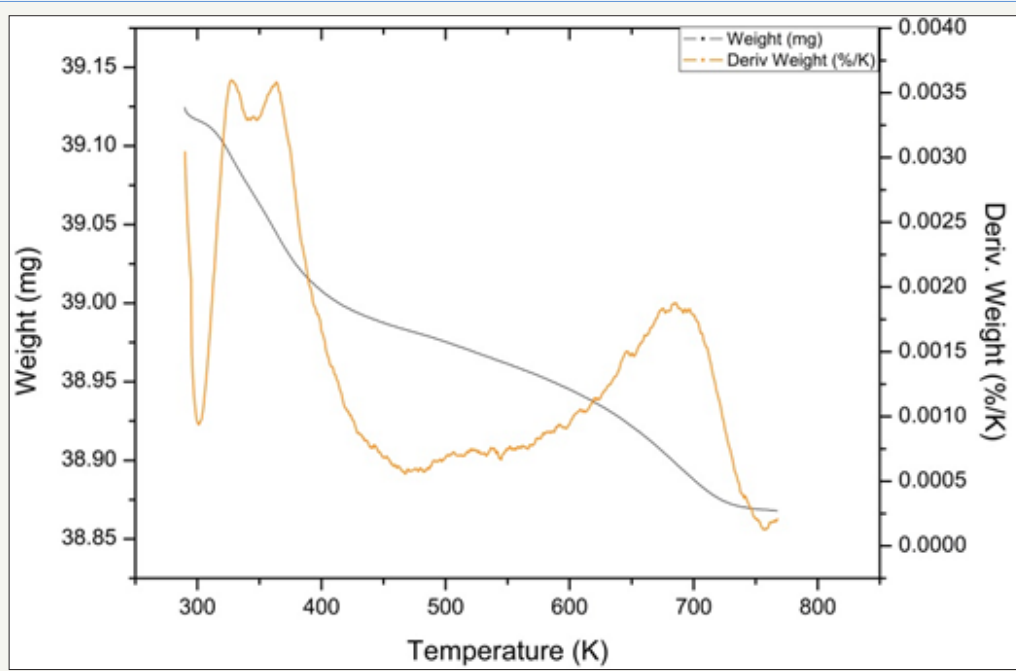

Figure 30: Post reaction TGA results for catalyst $2.1 \mathrm{Fe}$.

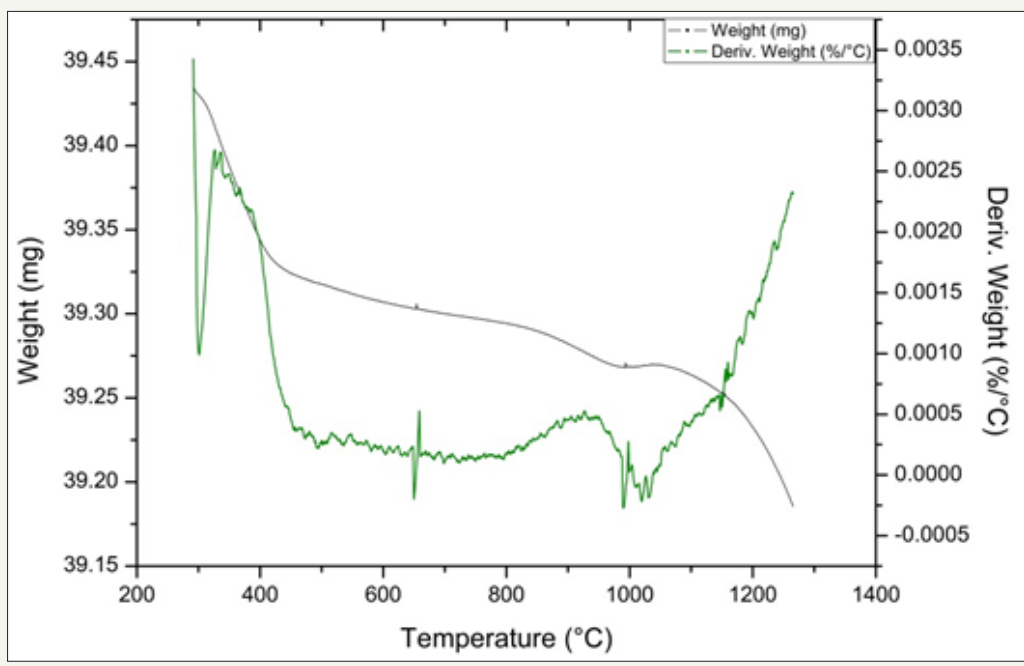

Figure 31: Post reaction TGA results for catalyst 2.2Fe. 


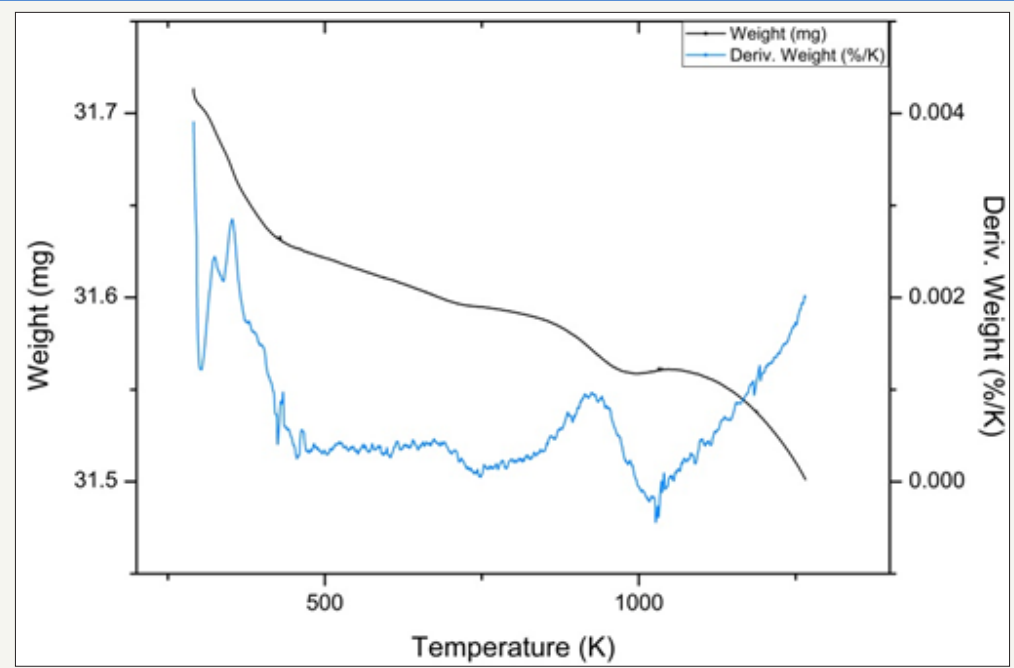

Figure 32: Post reaction TGA results for catalyst $2.3 \mathrm{Fe}$.

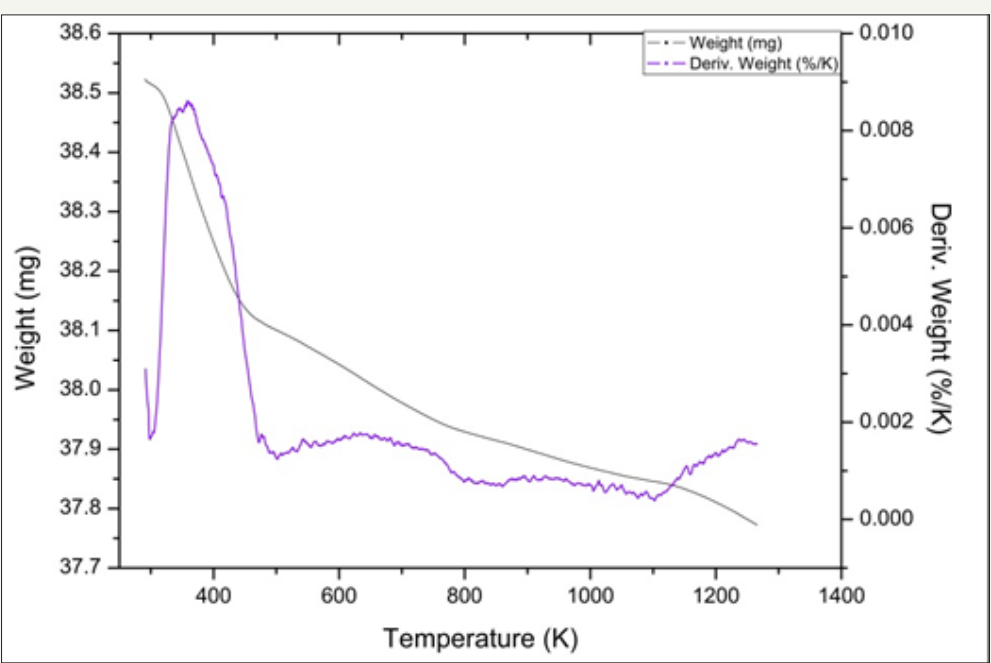

Figure 33: Post reaction TGA results for catalyst $2.4 \mathrm{Fe}$.

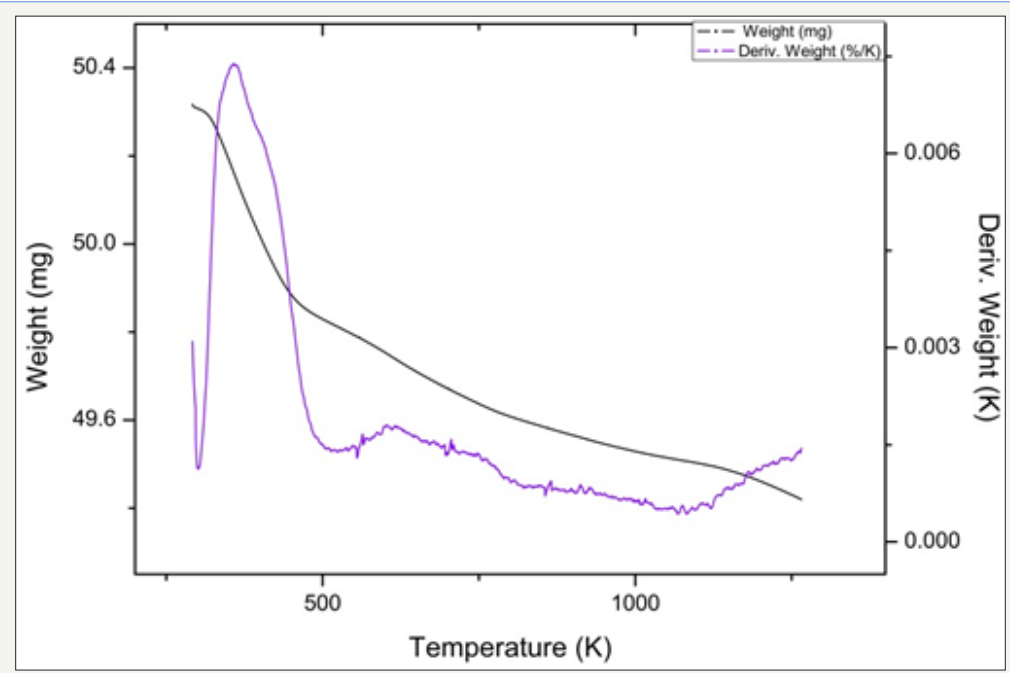

Figure 34: Post reaction TGA results for catalyst $2.5 \mathrm{Fe}$.

\section{Discussion}

Prior work has left the effect of addition of an excess of $\mathrm{Fe}^{3+}$ on a $\mathrm{ZnFe}_{2} \mathrm{O}_{4}$ catalyst in an ambiguous position, with reports of both positive and negative effects on catalytic activity and selectivity.
Through extensive catalyst testing and pre and post reaction characterization this work set out to determine the genuine effect of increasing the $\mathrm{Fe}: \mathrm{Zn}$ ratio on $\mathrm{ZnFe}_{2} \mathrm{O}_{4}$, both in terms of changes to the material itself and to its catalytic properties. Results from 
this work have shown that increasing the Fe: $\mathrm{Zn}$ ratio of a zinc ferrite reduces catalytic activity and selectivity. Our results are in agreement with the work of Armendáriz et al. [22] and Young-Min et al. [23] confirming that excess iron is deleterious and in contrast to the studies conducted by Zhang et. $\mathrm{Al} \mathrm{[19]} \mathrm{and} \mathrm{Xu} \mathrm{et.} \mathrm{Al} \mathrm{[20]} \mathrm{who}$ concluded, contradictory to our own findings, that the presence of an excess of $\mathrm{Fe}_{2} \mathrm{O}_{3}$ in a $\mathrm{ZnFe}_{2} \mathrm{O}_{4}$ catalyst improves catalytic activity. By thoroughly characterizing our catalysts' morphology and electronic properties the aim was to understand these differences. The targeted metal ion ratios were measured using atomic absorption measurements for the bulk and XPS for the ferrite surface. A good correlation was observed between target Fe: $\mathrm{Zn}$ ratio and that of the bulk ferrite however Fe: $\mathrm{Zn}$ ratios measured on the catalyst surface were shown to be notably higher than that of the bulk, a result of the ferrites small particle size, which has been shown to result in $\mathrm{Fe}^{3+}$ enriched surfaces, with surface ion concentrations different to that of the bulk [32].

XRD and Raman spectroscopy confirmed the zinc ferrite phase present in each of the six ferrite catalyst samples. Raman spectroscopy also showed the presence of an $\alpha-\mathrm{Fe}_{2} \mathrm{O}_{3}$ phase alongside each of the ferrites, however the secondary phase could only be identified by XRD at the higher Fe: Zn ratio ferrites. The occurrence of a $\mathrm{ZnFe}_{2} \mathrm{O}_{4} / \alpha-\mathrm{Fe}_{2} \mathrm{O}_{3}$ mixed phase, as-identified by XRD, was also documented in a study by Young-Min et al. [23], where it was observed that the mixed phase $\mathrm{ZnFe}_{2} \mathrm{O}_{4} / \alpha-\mathrm{Fe}_{2} \mathrm{O}_{3}$ had a reduced catalytic activity compared to pure $\mathrm{ZnFe}_{2} \mathrm{O}_{4}$. EPR spectroscopy highlighted no changes to the catalysts electronic structure with increased Fe: $\mathrm{Zn}$ ratio, suggesting that the additional $\mathrm{Fe}^{3+}$ ions were occupying the same electronic position in the spinel as they would in a stoichiometric zinc ferrite. In each case the only feature present in the spectra is a sharp, symmetrical resonance with $\mathrm{g}_{\text {eff }} \approx$ 2.02 for $2.0 \mathrm{Fe}$ and $2.1 \mathrm{Fe}$ which shifts to $\mathrm{g}_{\text {eff }} \approx 1.94$ for $2.2 \mathrm{Fe}-2.5 \mathrm{Fe}$. BET surface area analysis measured a surface area of $36 \mathrm{~m}^{2} \cdot \mathrm{g}^{-1}$ for the stoichiometric zinc ferrite, which corresponds well with literature values for zinc ferrite produced by co-precipitation in $\mathrm{NaOH}$ solution [23]. An initial increase in surface area from 36$71 \mathrm{~m}^{2} \cdot \mathrm{g}^{-1}$ and an increase in average pore diameter from 39 to $95 \AA$ were observed as the Fe: $\mathrm{Zn}$ ratio was increased from 2 to 2.3. Both parameters then showed a steady decrease with each subsequent increase in Fe: Zn ratio, however even at the highest Fe: Zn ratio tested the surface area and pore diameter was both greater than in the case of the stoichiometric zinc ferrite. Therefore any reduction in activity was not due to a reduction in available surface area or a change in electronic structure of the zinc ferrite. The reduction behaviour of the zinc ferrite catalysts was shown to change as the Fe: $\mathrm{Zn}$ ratio was increased. Catalysts with a lower Fe: $\mathrm{Zn}$ ratio $(2.0 \mathrm{Fe}$ and $2.1 \mathrm{Fe}$ ) showed three distinct areas of weight loss in line with those observed by Liang et al. [33] for $\mathrm{ZnFe}_{2} \mathrm{O}_{4}$. As the Fe: $\mathrm{Zn}$ ratio was increased there was loss of the reduction peak at $\sim 685 \mathrm{~K}$ and an increase in the overall percentage weight loss for each catalyst, as a result of an increased reduction peak at $\sim 670 \mathrm{~K}$. This indicates that the amount of labile oxygen that could be available for reaction increased with increasing Fe: Zn ratio. The suggested mechanism for the oxidative dehydrogenation of 1-butene [34] is a Mars-van
Krevelen type reaction where oxygen plays an important role in the cycle as it is being continually hydroxylated and removed from the catalyst as water before being replenished by gaseous oxygen. It would therefore be expected that increased oxygen lability would be beneficial to a zinc ferrite catalyst for this type of reaction. This is not the case however as there was a decrease in conversion and selectivity with increased Fe: Zn ratio and increased oxygen lability. This increased reducibility of the catalyst may however be a result of reduction of the secondary $\alpha-\mathrm{Fe}_{2} \mathrm{O}_{3}$ phase, which has been shown to be more readily reduced, under the conditions investigated, than $\mathrm{ZnFe}_{2} \mathrm{O}_{4}$ [35].

It was observed that throughout the time on stream, all of the catalysts tested were active as 1-butene oxidative dehydrogenation catalysts to produce 1, 3-butadiene. Conversion data for the $\mathrm{ODH}$ reaction carried out over each of the catalysts, (Figure 8) showed a clear decrease with increasing Fe: Zn ratio, with the stoichiometric catalyst having the highest overall conversion. As Fe: $\mathrm{Zn}$ ratio was increased from 2.3 to 2.5 a significant drop in conversion was observed, this may be a result of increased $\alpha-\mathrm{Fe}_{2} \mathrm{O}_{3}$ present as a distinct phase to the zinc ferrite, as shown in XRD and Raman data. Young Min et al. [23] noted the negative effect on catalyst activity of a secondary $\alpha-\mathrm{Fe}_{2} \mathrm{O}_{3}$ phase alongside $\mathrm{ZnFe}_{2} \mathrm{O}_{4}$ for a similar system. SEM data also shows the increased presence of structures present on the catalyst surface at higher Fe: Zn ratios, which may be influencing catalytic activity (Figure 4). Conversion data obtained for $\alpha / \gamma-\mathrm{Fe}_{2} \mathrm{O}_{3}$ as a 1-butene ODH catalyst under the same reaction conditions, revealed a conversion of $<1 \%$. From the 1,3 -butadiene and carbon dioxide yield it can be seen that, in contrast to results presented in studies by Zhang et al. [19] and Straguzzi et al. [36], $\alpha-\mathrm{Fe}_{2} \mathrm{O}_{3}$ is virtually inactive as a 1-butene ODH catalyst (Figure 11). Our results are in keeping with those of Makoto et al. [37] who observed a conversion of $3 \%$ for a 1-butene ODH reaction carried out over $\alpha / \gamma-\mathrm{Fe}_{2} \mathrm{O}_{3}$. It would therefore be expected that with the increasing appearance of an inactive $\alpha-\mathrm{Fe}_{2} \mathrm{O}_{3}$ phase alongside the active $\mathrm{ZnFe}_{2} \mathrm{O}_{4}$ phase we would observe a decrease in catalytic activity, as evidenced by conversion data presented in Figure 8.

From Figure 9 it is clear that increasing Fe: $\mathrm{Zn}$ ratio of a $\mathrm{ZnFe}_{2} \mathrm{O}_{4}$ results in a decrease in 1, 3-butadiene yield. Catalyst 2.0Fe, the stoichiometric zinc ferrite, showed the highest 1, 3-butadiene yield of the catalysts tested, whereas each subsequent increase in Fe: $\mathrm{Zn}$ ratio resulted in a drop in 1, 3-butadiene yield. The stoichiometric zinc ferrite also exhibited the highest overall 1, 3-butadiene selectivity, of $\sim 99 \%$ throughout time on stream, with the remaining $1 \%$ selectivity comprising of minor products such as butane and propane (Table 6). 1, 3-Butadiene selectivity can then be seen to decrease with increasing $\mathrm{Fe}^{3+}$ excess, with catalysts $2.4 \mathrm{Fe}$ and $2.5 \mathrm{Fe}$ showing the lowest selectivities. Figure 11 shows the yields of 1 , 3-butadiene and carbon dioxide for a 1-butene ODH reaction being carried out over a $\mathrm{Fe}_{2} \mathrm{O}_{3}$ catalyst, product yields are very low as a result of the low conversion. A carbon dioxide yield of $0.23 \%$ and 1 , 3-butadiene yield of $\sim 0.25 \%$ were observed throughout time on stream, making carbon dioxide and 1,3-butadiene the two major reaction products. In the tests over the non-stoichiometric catalysts the GC analysis detected small quantities of other hydrocarbons but 
the system was not sensitive to carbon dioxide, hence it is possible for carbon dioxide be the missing selectivity. To confirm that carbon dioxide could be the other product, the oxygen demand was calculated using the combustion of 1-butene, $\mathrm{C} 4 \mathrm{H} 8+6 \mathrm{O}_{2} \diamond 4 \mathrm{CO}_{2}$ $+4 \mathrm{H}_{2} \mathrm{O}$, given that this reaction requires six moles of oxygen per mole of 1-butene in comparison to the production of butadiene, which only requires half a mole of oxygen per mole of 1-butene. In all cases sufficient oxygen was available for all of the undetected selectivity to be carbon dioxide.

A variety of minor products were observed in each reaction: methane, ethane, propane, butane and isobutene. In each case these minor products made up $<1 \%$ of the total selectivity. Of these minor products, only butane was shown to exhibit a significant change in yield and selectivity with increased Fe: $\mathrm{Zn}$ ratio (Figure 10 and Table 7).When the reaction was run over the stoichiometric zinc ferrite, butane had a selectivity of $<1 \%$ throughout the time on stream, however this was shown to increase as Fe: Zn ratio increases, with a maximum selectivity of $\sim 7 \%$ obtained for catalyst $2.5 \mathrm{Fe}$ after $75 \mathrm{~h}$ on stream. This is a highly unusual result as it implies that there is a hydrogenation reaction taking place under oxidizing conditions. Butane has to be formed by the addition of hydrogen lost from 1-butene, if two 1-butene molecules were adsorbed in close proximity then the hydrogen could be transferred either across the surface, although this would require that the hydrogenation rate of 1, 3-butadiene was faster than the oxidation of hydrogen, or the hydrogen could be transferred by a concerted mechanism as in a trans-hydrogenation [38]. Whatever the mechanism it is clear that the site for this process is not present on stoichiometric zinc ferrite but occurs in the non-stoichiometric systems and increases in concert with the excess iron, suggesting a non-selective, second phase is present.

As the Fe: $\mathrm{Zn}$ ratio of the zinc ferrite catalysts was increased the presence of an $\alpha-\mathrm{Fe}_{2} \mathrm{O}_{3}$ phase became more pronounced in XRD, Raman and SEM data, whilst at the same time a decrease in selectivity towards 1, 3-butadiene was observed. With catalyst 2.0Fe, the stoichiometric zinc ferrite, no carbon dioxide was produced over the course of the reaction, but separate experiments examining $\alpha-\mathrm{Fe}_{2} \mathrm{O}_{3}$ as an independent catalyst showed a moderate selectivity towards carbon dioxide. Therefore as the catalyst Fe:Zn ratio is increased, some of the additional $\mathrm{Fe}^{3+}$ being supplied is being incorporated not into the spinel but is forming a separate $\alpha-\mathrm{Fe}_{2} \mathrm{O}_{3}$, as evidenced by the catalyst characterization. The $\alpha-\mathrm{Fe}_{2} \mathrm{O}_{3}$, phase has been shown by results in this paper and those in the literature to be inactive as a catalyst in the 1-butene ODH process, therefore the increased incorporation of $\alpha-\mathrm{Fe}_{2} \mathrm{O}_{3}$ into a $\mathrm{ZnFe}_{2} \mathrm{O}_{4}$ catalyst, particularly on the catalyst surface, would be expected to reduce catalytic activity, as shown in our 1-butene conversion results (Figure 8). It would also be expected that 1,3-butadiene selectivity would drop as a result of a competing combustion reaction catalyzed by the presence of $\alpha-\mathrm{Fe}_{2} \mathrm{O}_{3}$ on the catalyst surface. Studies by Zhang et al. [19], which show results indicating that a mixed phase $\mathrm{ZnFe}_{2} \mathrm{O}_{4} / \alpha-\mathrm{Fe}_{2} \mathrm{O}_{3}$ catalyst has increased catalytic activity compared to pure $\mathrm{ZnFe}_{2} \mathrm{O}_{4}$, unfortunatelydo not describe the other products of the reaction, or whether a competing combustion reaction was observed.
To determine what effect the reaction process has on the catalysts, post-reaction characterization was performed. Unfortunately, studies looking at similar systems only include very limited post reaction catalyst characterization for comparison [1820]. Post reaction XPS carried out on catalysts $2.0 \mathrm{Fe}$ and $2.5 \mathrm{Fe}$ show an increase in both the Fe: $\mathrm{Zn}$ ratio and the percentage of 02- present at the surface of both catalysts over the course of the reaction. BET surface area data for all of the post reaction catalysts showed a decrease in surface area, indicating sintering of the catalyst surface during the reaction. The reaction was repeated with a steam-only feed and a similar reduction in surface area was observed for the zinc ferrite. This indicates that the sintering is occurring as a result of interaction between the catalyst and the steam in the feed and not as a result of the ODH process itself. Such surface area decrease would typically result in an increase in catalyst particle size: this was confirmed by EPR spectroscopy. Evidence in the literature also suggests that as zinc ferrite particle size is decreased from the bulk there is a movement towards a more inverse spinel structure, therefore it would be expected that as the zinc ferrite sintered during reaction and the particle size increased, as evidenced by XRD and BET surface area results, that the EPR spectra should also broaden [16]. The observed EPR spectrum stems from the paramagnetic $\mathrm{Fe}^{3+}$ ions primarily located in the octahedral sites of the structure [39-41]. With nano sized particles showing a mixed spinel structure, where a proportion of $\mathrm{Fe}^{3+}$ ions are located in tetrahedral sites. This effects the spin coupling, coined exchange, between the two $\mathrm{Fe}^{3+}$ ions and the overall profile of the EPR spectrum. In normal spinels, the $\mathrm{Fe}^{3+}$ reside in adjacent octahedral where the $\mathrm{Fe}-\mathrm{O}-\mathrm{Fe}$ bond angle of $\sim 90^{\circ}$ gives rise to poor orbital overlap and an inherently weak exchange interaction [42]. In contrast, the linear $\mathrm{Fe}-\mathrm{O}-\mathrm{Fe}$ angle for a ferrite with half the $\mathrm{Fe}^{3+}$ in octahedral sites and the other half in tetrahedral sites gives rise to a very strong exchange interaction. This structure is ferrimagnetic because the octahedral and tetrahedral sub lattices are anti parallel and with twice as many octahedral sites than tetrahedral ones, the magnetic moment is uncompensated. It has previously been determined that stoichiometric zinc ferrite displays a short range anti ferromagnetic ordering at higher temperatures, which gives rise to the super paramagnetism at room temperature $[43,44]$. The prepared zinc ferrites are also super paramagnetic; hence it was necessary to dilute the samples in $\mathrm{ZnO}$ in order to carry out the EPR measurements in the $0.34 \mathrm{~T}$ magnetic fields. Exchange coupling leads to a narrowing of the EPR line width; hence the stronger the exchange interaction the narrower the line. For the pre-reaction catalysts, the narrow line width is indicative of a proportion of the $\mathrm{Fe}^{3+}$ in tetrahedral holes, with the stoichiometric zinc ferrite having the largest occupancy, which decreased with increasing Fe content. The contrast with the post-reaction samples is abundantly clear from the overlay presented in Figure 3. The substantially increase in the line width, which transverses the series incrementally from $10 \mathrm{mT}$ for stoichiometric $2.0 \mathrm{Fe}$ to $94 \mathrm{mT}$ for $2.5 \mathrm{Fe}$ confirms the reaction process leads to a mobilization the $\mathrm{Fe}^{3+}$ ions and decrease in their occupancy of the tetrahedral sites, giving the post-reaction zinc ferrite a more normal spinel structure, which is commensurate with larger particles 


\section{Conclusion}

The aim of this work was to determine the effect of increasing the Fe: $\mathrm{Zn}$ ratio of $\mathrm{ZnFe}_{2} \mathrm{O}_{4}$ on its catalytic activity for 1-butene ODH. We have clearly shown that as the Fe: $\mathrm{Zn}$ ratio was increased the catalytic activity and 1,3-butadiene selectivity were significantly reduced. A series of six zinc ferrite catalysts were produced with increasing Fe: Zn ratios. XRD and Raman of pre-reaction catalysts showed the presence of $\alpha-\mathrm{Fe}_{2} \mathrm{O}_{3}$ at even a small excess of Fe. SEM results also show the presence of structures present on the catalyst surface. The ferrites were tested as catalysts for the oxidative dehydrogenation of 1-butene and it was observed that with increasing Fe: Zn ratio, conversion, 1, 3-butadiene yield and 1, 3-butadiene selectivity decreased. Results from 1-butene ODH over a pure $\alpha-\mathrm{Fe}_{2} \mathrm{O}_{3}$ showed a low 1, 3-butadiene selectivity as a result of a competing combustion reaction producing carbon dioxide in agreement with the work of Kung [45]. It is therefore suggested that as $\alpha-\mathrm{Fe}_{2} \mathrm{O}_{3}$ was produced alongside the zinc ferrite phase, as the Fe: $\mathrm{Zn}$ ratio increased, it resulted in a decreased 1, 3-butadiene selectivity in favor of the production of carbon dioxide. Butane was also shown to be promoted by an increased Fe: $\mathrm{Zn}$ ratio in the catalyst, possibly due to a trans-hydrogenation reaction. All catalysts showed a deactivation over the course of the ODH reaction, which correlates with a decrease in surface area post-reaction as a result of sintering in the presence of steam and the movement of $\mathrm{Fe}^{3+}$ ions over the course of the reaction from tetrahedral to octahedral holes, moving towards a more normal spinel structure.

\section{Acknowledgement}

The authors would like to acknowledge funding for this project from Invista Textiles (UK) and the provision of a studentship for one of us (CB). X-ray Photoelectron Spectroscopy (XPS) was performedat the National EPSRC XPS Users' Service (NEXUS) at Newcastle University, an EPSRC Mid-Range Facility.

\section{References}

1. Armstrong HE, Miller AK (1886) The decomposition and genesis of hydrocarbons at high temperatures. I. The products of the manufacture of gas from petroleum. The Journal of the Chemical Society 49: 74-93.

2. White WC (2007) Butadiene production process overview. Chemico Biological Interactions 166(1-3): 10-14

3. Market Research Report (2014) 1,3 Butadiene (BD) market analysis by application (Butadiene Rubber, ABS, SBR, SB Latex, NBR, Hexamethylenediamine), bio-based opportunities and segment forecasts To 2020. Market Research Report.

4. Angelici CW, Weckhuysen BM, Bruijnincx PC (2013) Chemocatalytic conversion of ethanol into butadiene and other bulk chemicals. ChemSusChem 6(9): 1595-1614.

5. Finocchio E, Busca G, Ramis G, Lorenzelli V (1997) On the mechanism of the selective oxy-dehydrogenation of n-butenes to 1,3-butadiene on magnesium ferrite: an FT-IR study. Studies in Surface Science and Catalysis 110: 989-998.

6. Lee H, Jung JC, Song IK (2009) Factors affect on the reaction performance of the oxidative dehydrogenation of n-butene to 1,3-butadiene over znferrite catalysts. Catalysis Letters 133: 321-327.

7. Toledo JA, Bosch P, Valenzuela MA, Montoya A, Nava N (1997) Oxidative dehydrogenation of 1-butene over $\mathrm{ZnAl}$ ferrites. Jourrnal of Molecular Catalysis 125(1): 53-62

8. Lee H, Jung CJ, Kim H, Chung YM, Kim TJ, et al. (2008) Effect of divalent metal component (MeII) on the catalytic performance of $\mathrm{MeIFe}_{2} \mathrm{O}_{4}$ catalysts in the oxidative dehydrogenation of n-butene to 1,3-butadiene. Catalysis Letters 124: 364-368.

9. Gibson MA, Hightower JW (1976) Oxidative dehydrogenation of butenes over magnesium ferrite kinetic and mechanistic studies. Journal of Catalysis 41(3): 420-430.

10. Rennard RJ, Kehl WL (1971) Oxidative dehydrogenation of butenes over ferrite catalysts. Journal of Catal 21(3): 282-293.

11. Kung HH, Kung MC (1985) Selective oxidative dehydrogenation of butenes on ferrite catalysts. Advances in Catalysis 33: 159-198.

12. Park JH, Row K, Shin CH (2013) Oxidative dehydrogenation of 1-butene to 1,3-butadiene over $\mathrm{BiFe}_{0.65} \mathrm{Ni}_{\mathrm{x}} \mathrm{Mo}$ oxide catalysts: Effect of nickel content. Catalysis Communications 31: 76-80.

13. Hong E, Park JH, Shin CH (2016) Oxidative dehydrogenation of n-butenes to 1,3-butadiene over bismuth molybdate and ferrite catalysts: a review. Catalysis Surveys from Asia 20(1): 23-33.

14. Yan W, Kouk QY, Luo J, Liu Y, Borgna A (2014) Catalytic oxidative dehydrogenation of 1-butene to 1,3-butadieneusing $\mathrm{CO}_{2}$. Catalysis Communication 46: 208-212.

15. Putnis A (1992) An introduction to mineral sciences. Cambridge University Press,USA.

16. Anantharaman MR, Jagatheesan S, Malini KA, Sindhu A, Narayanasamy A, et al. (1998) On the magnetic properties of ultra-fine zinc particles. Journal of Magnetism and Magnetic Materials 189(1): 83-88.

17. Hochepied JF, Bonville P, Pileni MP (2000) Nonstoichiometric zinc ferrite nanocrystals: syntheses and unusual magnetic properties. Journal of Physical Chemistry 104(5): 905-912.

18. Chung YM, Kwon YT, Kim TJ, Lee SJ, Oh SH (2009) Prevention of catalyst deactivation in the oxidative dehydrogenation of n-butene to 1,3-butadiene over zn-ferrite catalysts. Catalysis Letters 131: 579-586.

19. Zhang M, Lan R, Liu J, Cheng X, Zhou W (1992) Phase cooperation between $\mathrm{ZnFe}_{2} \mathrm{O}_{4}$ and $\alpha-\mathrm{Fe}_{2} \mathrm{O}_{3}$ phases of ferrite catalysts in the oxidative dehydrogenation on n-butenes. Journal of the Chemistry Society Faraday Transactions 88(4): 637-644.

20. Xu WQ Yin YG, Li GY, Chen S (1992) Roles of spinel and maghemite phases in the oxidative dehydrogenation of butene over iron complex oxides. II. Epitaxy and synergy between $\gamma$ - $\mathrm{Fe}_{2} \mathrm{O}_{3}$ and ferrite spinels. Applied Catalysis A: General 89(2): 131-142.

21. Miao C, Wu W, Fan Z, Zeng T, Ma C, et. al (2014) Catalyst for the oxidative dehydrogenation of butene to butadiene and preparation process thereof. China Petroleum \& Chemical Corporation and Shanghai Research Institute of Petrochemical Technology Sinopec.

22. Armendáriz H, Aguilar Rios G, Salas P, Valenzuela MA, Schifter I (1992) Oxidative dehydrogenation of $\mathrm{n}$-butane on iron-zinc oxide catalysts. Applied Catalysis A: General 92(1): 29-38.

23. Young Min C, Kwon YT, Kim TJ, Lee SJ, Oh SH (2009) Factors affect on the reaction performance of the oxidatie dehydrogenation of n-butene to 1,3-butadiene over zn-ferrite catalysts. Catalysis Letters 130: 417-423.

24. Wang Z, Schiferl D, Zhao Y, Oneill HSC (2003) High pressure raman spectroscopy of spinel-type ferrite $\mathrm{ZnFe}_{2} \mathrm{O}_{4}$. Journal of Physics and Chemistry of Solids 64(12): 2517-2523.

25. Singh JP, Srivastava RC, Agrawal HM, Kumar R (2011) Micro-Raman investigation of nanosized zinc ferrite: effect of crystallite size and fluence of irradiation. Journal of Raman Spectroscopy 42(7): 1510-1517. 
26. Shim SH, Duffy TS (2002) Raman spectroscopy of $\mathrm{Fe}_{2} \mathrm{O}_{3}$ to $62 \mathrm{GPa}$ American Mineralogist 87: 318-326.

27. Lin X, Zhang Y, Yin L, Chen C, Zhan Y, et al. (2014) Characterization and catalytic performance of copper-based wgs catalysts derived from copper ferrite. International Journal of Hydrogen Energy 39(12): 64246432.

28. Kamari MH, Naseri GM, Saion BE (2014) A novel research on behavior of zinc ferrite nanoparticles in different concentration of poly(vinyl pyrrolidone) (PVP). Metals 4(2): 188-129.

29. Ren P, Zhang J, Deng H (2009) Preparation and microstructure of spinel zinc ferrite $\mathrm{ZnFe}_{2} \mathrm{O}_{4}$ by Co-precipitation method. Journal of Wuhan University of Technology Mater Sci Ed 24(6): 927-930

30. Bleaney ABA (1970) Electron Paramagnetic Resonance of Transition Ions. Clarendon Press, Oxford, UK.

31. Spence RR (2014) The Oxidehydrogenation of C-4 Alkenes over Zinc Ferrite. University of Glasgow, Scotland, UK.

32. Ballarini N, Cavani F, Passeri S, Pesaresi L, Lee A, et al. (2009) Phenol methylation over nanoparticulate $\mathrm{CoFe}_{2} \mathrm{O}_{4}$ inverse spinel catalysts: The effect of morphology on catalytic performance. Applied Catalysis A: General 366(1): 184-192.

33. Liang M, Kang W, Xie K (2009) Comparison of reduction behavior of $\mathrm{Fe}_{2} \mathrm{O}_{3}, \mathrm{ZnO}$ and $\mathrm{ZnFe}_{2} \mathrm{O}_{4}$ by TPR technique. Journal of Natural Gas Chemistry 18(1): 110-113.

34. Lee H, Jung JC, Song IK (2009) Oxidative dehydrogenation of n-butene to 1,3-butadiene over sulfated $\mathrm{ZnFe}_{2} \mathrm{O}_{4}$ catalyst. Catalysis Letters $133(3-4)$ 321-327.

35. Valenzuela MAB, Bosch P, Jimmenez Becerrill J, Quiroz O, Paez AI (2002) Preparation, characterization and photocatalytic activityof $\mathrm{ZnO}, \mathrm{Fe}_{2} \mathrm{O}_{3}$ and $\mathrm{ZnFe}_{2} \mathrm{O}_{4}$. Journal of Photochemistry and Photobiology A: Chemistry 148(1-3): 177-182.
36. Straguzzi GI, Bischoff KB, Koch TA, Schuit GCA (1987) Selective oxidation catalysts containing antimony for the conversion of 1-butene to butadiene: II. Selective oxidation of 1-butene and CO. Journal of Catalysis 104(1): 47-58.

37. Makoto M, Sakata K, Ueda F, Nazawa Y, Yoneda Y (1980) Catalytic properties of iron oxide. III. Oxidative dehydrogenation of butenes over iron oxide catalysts. The Chemical Society of Japan 53: 648-652.

38. Garba MD, Jackson SD (2017) Catalytic upgrading of refinery cracked products by trans-hydrogenation: a review. Applied Petrochemical Research 7(1): 1-8.

39. Kong L, Jiang Z, Xiao T, Lu L, Jones MO, et al. (2011) Exceptional visiblelight-driven photocatalytic activity over $\mathrm{BiOBr}-\mathrm{ZnFe}_{2} \mathrm{O}_{4}$ heterojunctions. Chemical Communications 47(19): 5512-5514.

40. Singh JP, Srivastava RC, Agrawal HM, Kushwaha RPS, Chand P, et al. (2008) EPR Study of Nanostructured Zinc Ferrite. International Journal of Nanoscience 7(1): 21-27.

41. Zhang P, Phan TL, Yu SC (2012) Electron-spin-resonance study of polycrystalline Fe-doped ZnO ceramics. Journal of the Korean Physical Society 61(10): 1563-1567.

42. Bercoff PG, Bertorello HR (1997) Exchange constants and transfer integrals of spinel ferrites. Journal of Magnetism and Magnetic Materials 169(3): 314-322.

43. Bean CP, Livingston JD (1959) Superparamagnatism. Journal of Applied Physics 30: S120-S129.

44. Köseoglu Y, Yildiz H, Yilgin R (2012) Synthesis, characterization and superparamagnetic resonance studies of $\mathrm{ZnFe}_{2} \mathrm{O}_{4}$ nanoparticles. Journal of Nanoscience and Nanotechnology 12(3): 2261-2269.

45. Yang BL, Kung MC, Kung HH (1984) Reasons for the different selectivities in the selective oxidation of butene on $\alpha$ - and $\gamma-\mathrm{Fe}_{2} \mathrm{O}_{3}$. Journal of Catalysis 89(1): 172-176.
Creative Commons Attribution 4.0 International License

For possible submissions Click Here

\section{Submit Article}

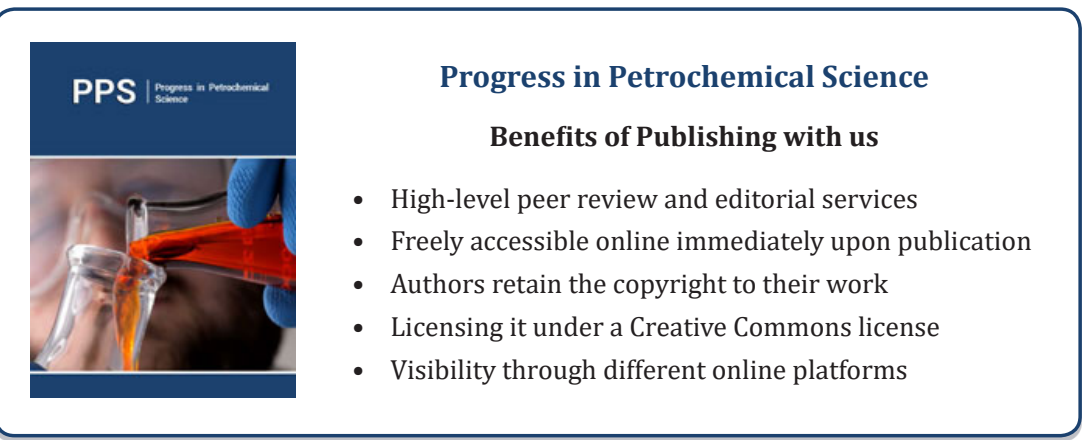

